\title{
HFIR SiC Bowing Test Ready to Insert
}

Nuclear Technology

Research and Development

Prepared for

U.S. Department of Energy Nuclear Technology R\&D Program Advanced Fuels Campaign

Authors:

Christian M. Petrie, Josina W. Geringer, Adam James, Kurt Smith, Joseph R. Burns, Annabelle G. Le Coq, Nicholas Russell, Christian P. Deck, Takaaki Koyanagi, Yutai Katoh Oak Ridge National Laboratory

March 2021 M2FT-21OR020203041 



\section{DISCLAIMER}

This information was prepared as an account of work sponsored by an agency of the U.S. Government. Neither the U.S. Government nor any agency thereof, nor any of their employees, makes any warranty, expressed or implied, or assumes any legal liability or responsibility for the accuracy, completeness, or usefulness, of any information, apparatus, product, or process disclosed, or represents that its use would not infringe privately owned rights. References herein to any specific commercial product, process, or service by trade name, trade mark, manufacturer, or otherwise, does not necessarily constitute or imply its endorsement, recommendation, or favoring by the U.S. Government or any agency thereof. The views and opinions of authors expressed herein do not necessarily state or reflect those of the U.S. Government or any agency thereof. 



\section{ACKNOWLEDGEMENTS}

This research was sponsored by the Advanced Fuels Campaign (AFC) Program of the US Department of Energy (DOE), Office of Nuclear Energy. Neutron irradiation in the High Flux Isotope Reactor (HFIR) is made possible by the Office of Basic Energy Sciences, US DOE. The report was authored by UT-Battelle under Contract No. DE-AC05-00OR22725 with US DOE. David Bryant (Oak Ridge National Laboratory) performed the specimen engraving and experiment assembly. Nathan Capps and Jacob Gorton (Oak Ridge National Laboratory) performed technical reviews of the report and provided helpful comments. Maureen Searles (Oak Ridge National Laboratory) performed the HFIR safety review and wrote the experiment authorization basis document. 


\section{SUMMARY}

This report describes the successful assembly of a High Flux Isotope Reactor (HFIR) irradiation experiment designed to assess radiation-induced lateral bowing of silicon carbide fiber-reinforced, silicon carbide matrix composite ( $\mathrm{SiC} / \mathrm{SiC})$ components under a radial fast neutron flux gradient. Excessive bowing of a $\mathrm{SiC} / \mathrm{SiC}$ channel box in a boiling water reactor could potentially interfere with control blade movements. Similar concerns exist for $\mathrm{SiC} / \mathrm{SiC}$ fuel cladding in light water reactors. The experiment described herein will provide experimental validation of the structural response of a miniature $\mathrm{SiC} / \mathrm{SiC}$ channel box and tube specimens with pressurized water reactor diameters during irradiation. The significant radial fast neutron flux gradients that exist in the permanent reflector of HFIR were characterized using detailed three-dimensional neutronic calculations. The three-dimensional displacement damage dose rate profile and the resulting volumetric swelling in $\mathrm{SiC}$ were used as inputs to structural analyses that predicted the deformation and stresses in the channel box specimen. The specimens were thoroughly characterized prior to irradiation using traditional dimensional inspection and surface profilometry so that these measurements can later be compared with similar measurements that will be made post-irradiation to determine radiation-induced deformations. Furthermore, fine engraving markers were inscribed along all outer surfaces of the specimen and mapped using a digital microscope and a three-dimensional stage. This technique allowed for accurate measurements of the marker spacings, which can be compared with similar measurements that will be made post-irradiation to provide local radiation-induced strain mapping. The experiment was successfully assembled and is scheduled for insertion during HFIR cycle 492, which is currently scheduled to run from May 25, 2021 to June 18, 2021. 
HFIR SiC Bowing Test Ready to Insert

March 2021 


\section{CONTENTS}

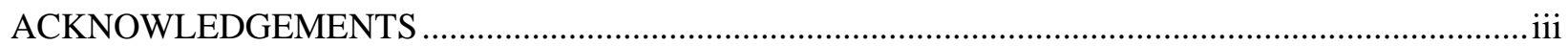

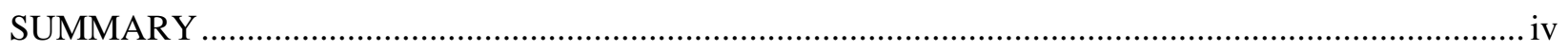

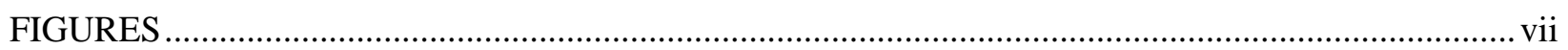

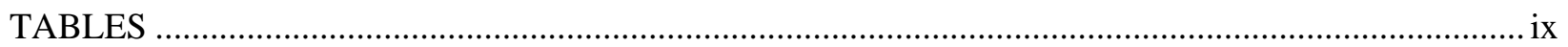

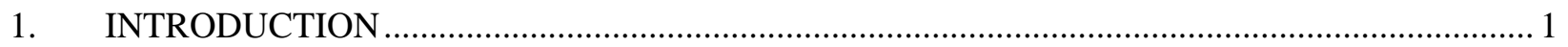

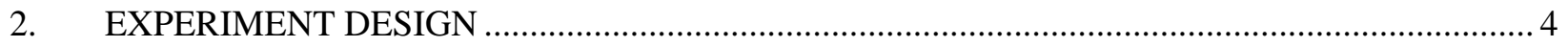

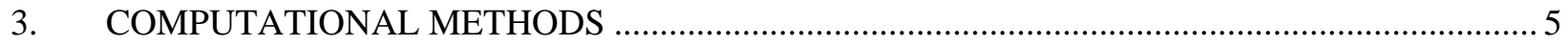

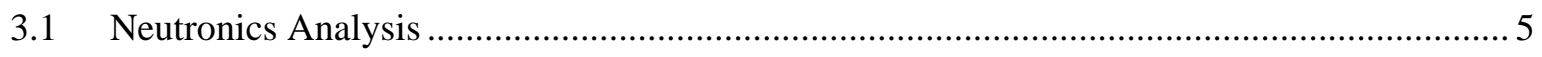

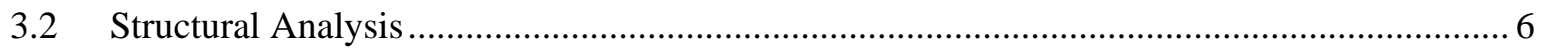

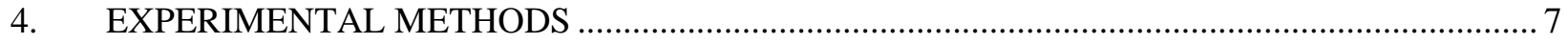

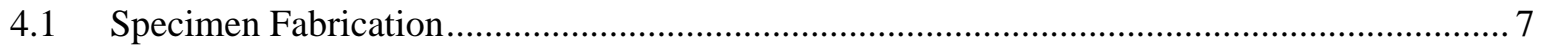

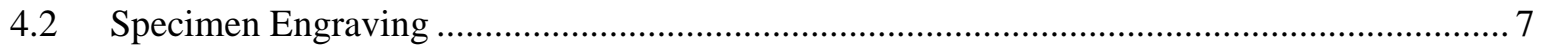

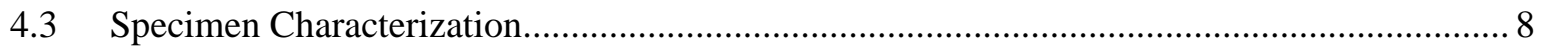

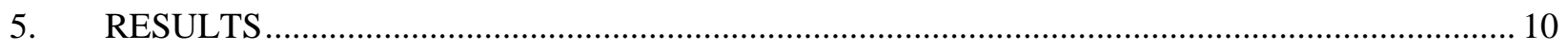

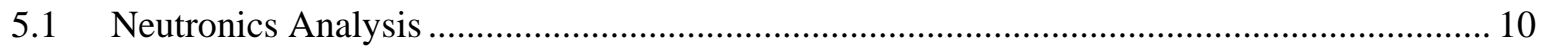

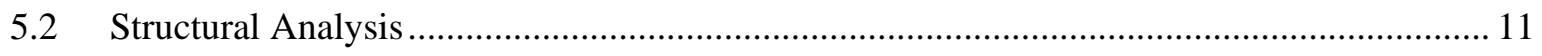

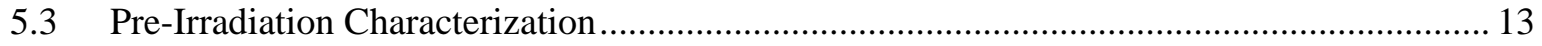

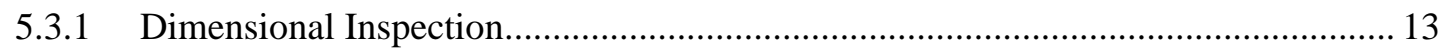

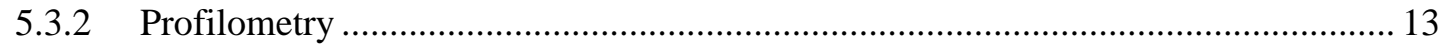

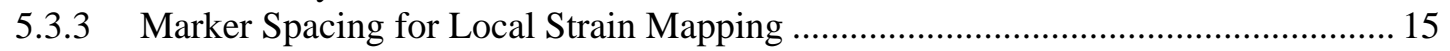

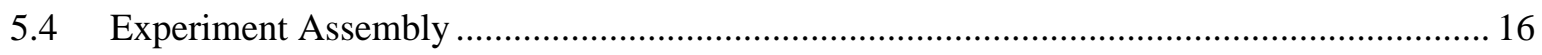

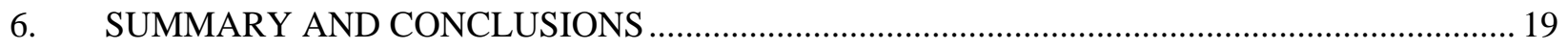

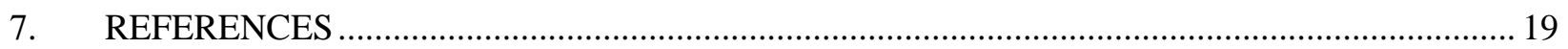

APPENDIX A. MEASURED LOCATIONS OF ENGRAVED MARKERS AND EXPERIMENT FABRICATION DOCUMENTATION 


\section{FIGURES}

Figure 1. Illustration (not to scale) of BWR channel box showing how a gradient in fast neutron flux $\left(\varphi_{\text {fast }}\right)$ in the $X$ direction results in differential neutron swelling across the channel box, causing lateral bowing. Bowing could obstruct coolant flow or interfere with control blade movements.

Figure 2. (a) Temperature- and dose-dependent volumetric and linear swelling of $\mathrm{SiC}$ [4]; (b) differential volumetric swelling and resulting lateral bowing vs. time and dose for various fast neutron flux gradients $\left(\Delta \varphi_{\text {fast }}\right)$ across the width of a channel box; (c) differential volumetric swelling and resulting lateral bowing vs. time and dose for various temperature gradients $(\Delta T)$ across the width of a channel box..................................... 3

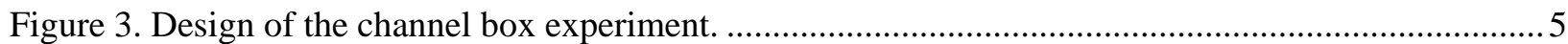

Figure 4. Structural model with displacement constraints and finite element mesh.

Figure 5. (a) Picture of the channel box, (b) two-dimensional radiographs, and (c) a threedimensional reconstruction of a section of a similar channel box obtained using $\mathrm{x}$-ray computed tomography. 7

Figure 6. Photograph (a) of the engraved channel box specimen; (b, c) closer views of the engraved markers and (d) a processed image of a single marker. 8

Figure 7. Labeling for dimensional inspection. 9

Figure 8. Pictures showing the translation stage that is used for both $(\mathrm{a}, \mathrm{b})$ local strain measurements with a digital microscope and (c) bowing measurements with an optical profilometer.

Figure 9. $(\mathrm{a}, \mathrm{b}) \mathrm{BOC}$ and $\mathrm{EOC}$ dose rates, respectively, at $\mathrm{Y}=0$ and various $\mathrm{X}$ vs. $\mathrm{Z}$ showing simulated data (solid lines) and fits (dashed lines); (c) 3D BOC dose rates at $Y=0$ vs. $X$ and $\mathrm{Z}$ showing simulated data and fits; (d) dose rate and volumetric swelling at $\mathrm{Y}=0$, $\mathrm{Z}=0$ vs. $\mathrm{X}$ determined using the fit after one and two HFIR cycles. The center of the HFIR core is in the positive $\mathrm{X}$ direction.

Figure 10. Simulated channel box bowing after two HFIR cycles showing (a) lateral displacement $\mathrm{U}_{\mathrm{X}}$ (in $\mathrm{m}$ ), with visual deformations artificially scaled by a factor of 10 , and (b, c, d) normal stresses (in Pa) with visual deformations artificially scaled by a factor of 50 .

Figure 11. Lateral bowing profiles determined using FEA and analytical equations after 1 and 2 HFIR cycles.

Figure 12. Profilometry calibration scans of (a) a straight stainless steel bar and (b) a dummy aluminum square channel with a nominally $0.76 \mathrm{~mm}$ bow introduced by bending around a mandrel.

Figure 13. Profile measurements for the channel box specimen showing (a) measured data (solid lines) and filtered data (dashed lines), and (b) only the filtered data.

Figure 14. Measured engraved marker locations showing (a) the configuration for the various specimen faces and (b) the measured marker locations. The outer surfaces of each face are shown as dashed black lines. The single red marker on face C3 D3 is questionable because one coordinate is thought to have been transposed during the recording process. Because this is not certain, this marker has been flagged 16

Figure 15. Photographs of the holder assembly. 


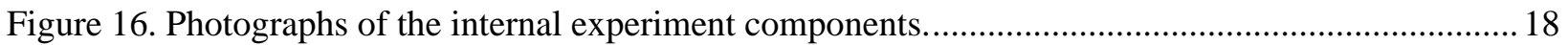

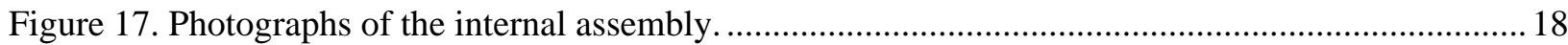




\section{TABLES}

Table 1. Fitting parameters for the simulated dose rate distributions. ................................................... 11

Table 2. Summary of pre-irradiation dimensional inspections. ............................................................... 13 



\section{HFIR SiC BOWING TEST READY TO INSERT}

\section{INTRODUCTION}

Silicon carbide ( $\mathrm{SiC}$ ) fiber-reinforced, $\mathrm{SiC}$ ceramic matrix composites ( $\mathrm{SiC} / \mathrm{SiC}$ composites) have long been considered for use in a wide range of nuclear applications [1] because of their high strength [2, 3] and dimensional stability $[4,5]$ under irradiation and at high temperatures, and their minimal neutron absorption [6]. These materials also exhibit superior oxidation kinetics in steam and air environments compared with most metal alloys and other high-temperature materials such as graphite [7, 8]. These characteristics make $\mathrm{SiC} / \mathrm{SiC}$ composites attractive both for advanced high-temperature reactors [9] and for improved accident tolerance in light water reactors (LWRs) [10-12]. One of the primary benefits associated with $\mathrm{SiC} / \mathrm{SiC}$ composites and other accident-tolerant fuels (ATFs) is the mitigation of significant heating and hydrogen generation caused by exothermic steam oxidation reactions with zirconium $(\mathrm{Zr})$-based fuel cladding during severe accidents, particularly beyond design basis accidents [13].

The international effort to deploy ATFs has gained much attention over the past decade, and SiC/SiC composite fuel cladding remains an attractive option if concerns related to hydrothermal corrosion [14-16] and fission product retention during irradiation with significant thermal gradients [17-22] can be resolved. In addition to fuel cladding, the accident tolerance of other core internal structures has been considered as a part of a broader effort to reduce the mass of $\mathrm{Zr}$ in LWRs to ultimately mitigate the consequences of severe accidents and allow more time for operator intervention [23]. Although all core internal structures must demonstrate acceptable corrosion rates, the requirements for maintaining hermeticity may not be as stringent for many in-core components. Examples of $\mathrm{SiC} / \mathrm{SiC}$ components that could replace current $\mathrm{Zr}$ components include channel boxes in boiling water reactors (BWRs) and control rod and instrument guide tubes in pressurized water reactors (PWRs). BWR channel boxes provide structure to the core and prevent hydraulic communication between adjacent channels [24].

Other than hydrothermal corrosion issues, the primary concern for $\mathrm{SiC} / \mathrm{SiC}$ composite core internal structures is radiation-induced lateral bowing [23]. Bowing is a concern even for current Zr-based channel boxes because any distortion of the channel box could obstruct coolant flow or interfere with control blade movements. The mechanism driving lateral bowing of $\mathrm{SiC} / \mathrm{SiC}$ composite structures is differential neutron radiation swelling of $\mathrm{SiC}$ in the presence of fast neutron flux gradients. Neutron radiation swelling of $\mathrm{SiC}$, and its temperature and dose dependence, are well characterized $[1,4,25]$, particularly in the point defect swelling regime $\left(\sim 200-1,000^{\circ} \mathrm{C}\right)$ that spans the range of interest for LWR applications. Figure 1 shows a schematic (not to scale) of four BWR channel boxes surrounding a single control blade. Figure 1 also illustrates how a gradient in fast neutron flux $\left(\varphi_{\text {fast }}\right)$ results in differential neutron swelling across the channel box, causing lateral bowing. Gradients would be expected to be more significant for fuel assemblies located near the periphery of the core, but significant gradients could exist elsewhere, depending on the distributions of burnup and enrichment within the core.

Figure 2a shows a model [4] for radiation-induced swelling of $\mathrm{SiC}$ as a function of dose in displacements per atom, or dpa. Differential swelling is caused by spatial variations in dose (or fast neutron fluence) or temperature. In the former case, the difference in dose on two opposite faces of a component increases linearly as a function of time. This causes the differential swelling to increase until the swelling starts to saturate on the face with the higher dose rate; eventually, the swelling on the opposite face catches up and the differential swelling approaches zero. Differential swelling is plotted in Figure $2 b$ as a function of time in a BWR assuming a maximum dose rate of $4 \mathrm{dpa} /$ year at a constant temperature $\left(300^{\circ} \mathrm{C}\right)$ with the variation in fast neutron flux $\Delta \varphi_{\text {fast }}$ across the channel box as a parameter. Using small-angle approximations and assuming isotropic swelling, it can be shown that the geometric relationship between the maximum lateral 
bowing $\Delta x_{\max }$ of a channel box — with length $L$ and cross-sectional width $W$-and the differential swelling $\left(\frac{d V}{V}\right)_{\text {diff }}$ is

$$
\Delta x_{\max }=\frac{L^{2}\left(\frac{d V}{V}\right)_{d i f f}}{24 W},
$$

with a maximum radius of curvature $(R)$ equal to

$$
R=\frac{3 W}{\left(\frac{d V}{V}\right)_{d i f f}}
$$

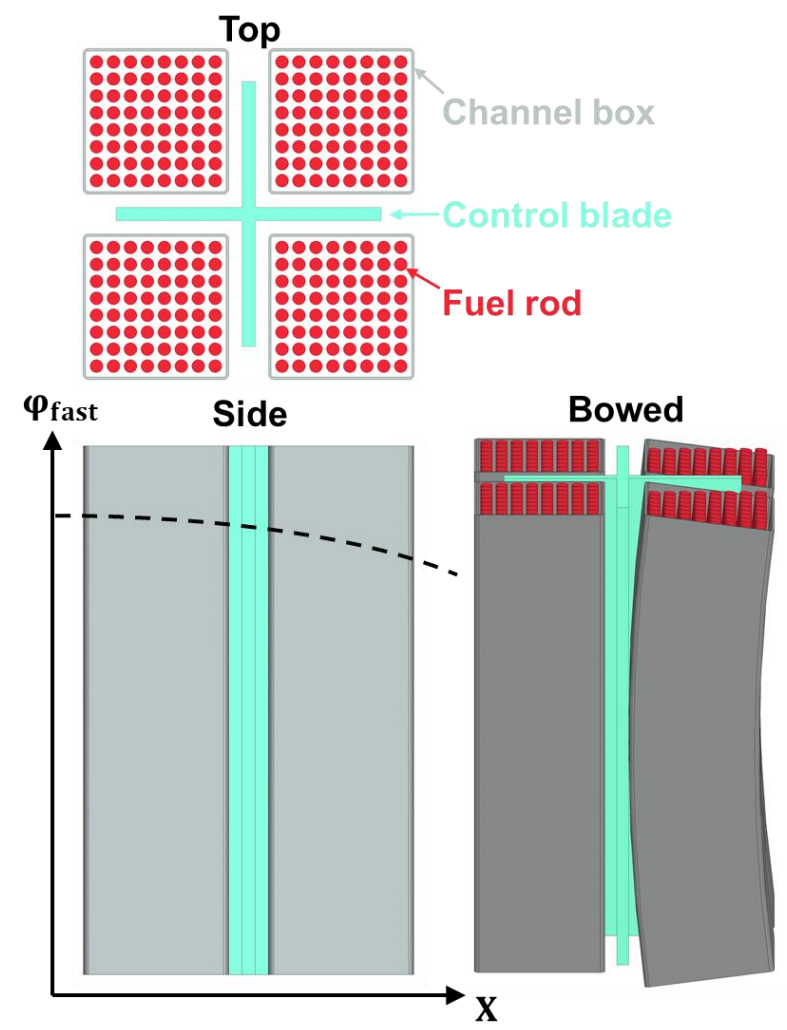

Figure 1. Illustration (not to scale) of BWR channel box showing how a gradient in fast neutron flux $\left(\varphi_{\text {fast }}\right)$ in the $X$ direction results in differential neutron swelling across the channel box, causing lateral bowing. Bowing could obstruct coolant flow or interfere with control blade movements.

In addition to the differential swelling, Figure $2 \mathrm{~b}$ shows the bowing for a BWR channel box calculated using Eq. (1) assuming $L=3,800 \mathrm{~mm}$ and $W=140 \mathrm{~mm}$ [23]. Figure $2 \mathrm{~b}$ shows that unconstrained differential swelling could cause lateral bowing that exceeds the allowable bowing of approximately $5 \mathrm{~mm}$ within $\sim 10$ days of operation if $\Delta \varphi_{\text {fast }}$ is greater than $\sim 20 \%$. According to Yueh et al, about a dozen fresh channels experience flux gradients between 25 and 29\% [23]. While spatial gradients in fast neutron flux may cause temporary bowing of a BWR channel box, spatial variations in temperature across the width of a channel box can result in permanent bowing due to differential swelling that exists even after saturation (see Figure 2a). Figure $2 \mathrm{c}$ shows the differential swelling and resulting channel bow as a function of irradiation time and dose with the temperature difference across the channel $\Delta T$ as a parameter. Figure $2 \mathrm{c}$ shows that even for relatively large temperature variations of up to $15^{\circ} \mathrm{C}$, the resulting lateral bowing is less than $3 \mathrm{~mm}$. For comparison, high-fidelity thermal hydraulic simulations predict the $\Delta T$ will be closer to $2.5^{\circ} \mathrm{C}$ [26]. 
Therefore, spatial variations in neutron flux are expected to be more likely to result in significant channel box bowing than spatial variations in temperature. Previous work has shown that circumferential temperature variations in $\mathrm{SiC} / \mathrm{SiC}$ fuel cladding of up to 8\% can result in lateral bowing of $6.2 \mathrm{~mm}$ [27].
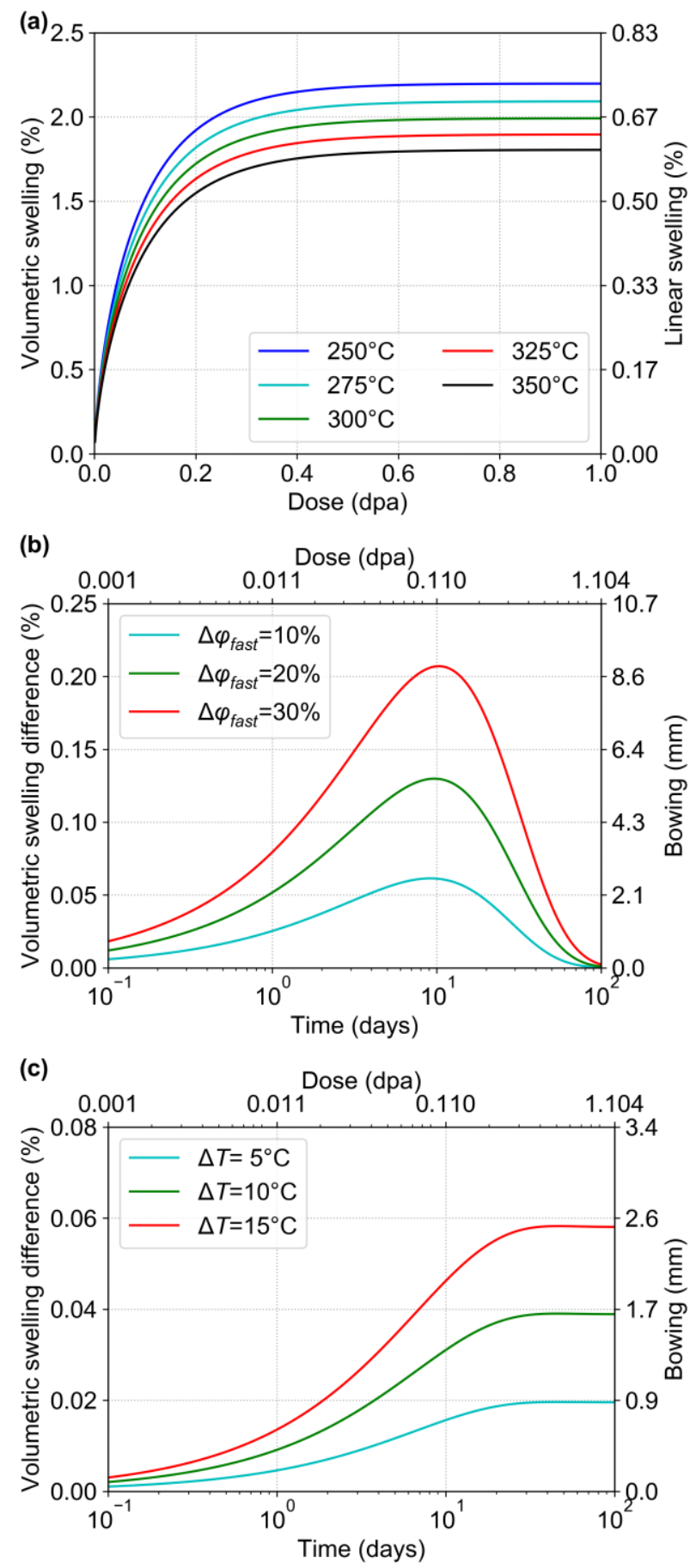

Figure 2. (a) Temperature- and dose-dependent volumetric and linear swelling of SiC [4]; (b) differential volumetric swelling and resulting lateral bowing vs. time and dose for various fast neutron flux gradients $\left(\Delta \varphi_{\text {fast }}\right)$ across the width of a channel box; (c) differential volumetric swelling and resulting lateral bowing vs. time and dose for various temperature gradients $(\Delta T)$ across the width of a channel box. 
Although this simplistic approach provides reasonable estimates for the expected channel box bowing and its dependence on temperature, dose, and spatial variations in both parameters, there are several factors that it does not consider. This approach ignores the effects of the channel box's stiffness, mechanical constraints imposed by the fuel rods and surrounding structural materials, and other phenomena such as matrix microcracking and irradiation creep. Recently, high-fidelity finite element analyses (FEAs) have been performed to asses bowing of a $\mathrm{SiC} / \mathrm{SiC}$ channel box with representative thermal-hydraulic, neutronic, and structural boundary conditions [26]. However, to date, there have been no experimental data to validate the thermomechanical models. This work describes an irradiation experiment to measure the lateral bowing of a miniature $\mathrm{SiC} / \mathrm{SiC}$ channel box that was fabricated by General Atomics (GA). The channel box will be irradiated in the reflector of the High Flux Isotope Reactor (HFIR) at Oak Ridge National Laboratory (ORNL). In the reflector positions, there exist significant radial fast neutron flux gradients to drive a swelling differential. The results of this experiment will be used to improve the understanding of unconstrained $\mathrm{SiC} / \mathrm{SiC}$ deformation and validate thermomechanical models that can simulate bowing with and without the effects of mechanical constraints imposed by the fuel and surrounding structural components. The irradiation will also be conducted at HFIR coolant temperatures $\left(50-60^{\circ} \mathrm{C}\right)$, as opposed to typical BWR temperatures. This approach prevents the need to perform a complex experiment that includes representative temperatures, dose rate distributions, and mechanical constraints. This report describes the design of the irradiation experiment, pre-irradiation characterization, and successful assembly.

\section{EXPERIMENT DESIGN}

The channel box bowing experiment is being performed in the permanent reflector of HFIR, which is a beryllium-reflected, pressurized, light water-cooled and moderated flux trap-type reactor [28, 29]. The channel box experiment will be irradiated in a large Vertical Experiment Facility (VXF) in the HFIR reflector. The reflector effectively thermalizes neutrons that leak from HFIR's core, resulting in significant radial gradients in the fast neutron flux, conditions ideal for driving bowing due to differential radiation swelling. The experiment design allows for a miniature channel box specimen and two tube specimens to be directly exposed to the reactor coolant, which flows through the experiment from top to bottom at a temperature in the range of $50-60^{\circ} \mathrm{C}$. Pre-irradiation characterization of these specimens is covered by a separate programmatic activity and will therefore be documented in a separate report. All specimens will be irradiated for up to two HFIR cycles, which are each approximately 25 days in duration.

The irradiation experiment design is shown in Figure 3. The irradiation vehicle is a two-piece aluminum holder that, when welded together, results in a cylindrical assembly with internal cutouts for the specimens. The orifice at the bottom of the holder controls the coolant flow rate that enters from the top of the experiment. The miniature channel box and tube specimens are assembled inside of the holder cutout. The nominal dimensions of the miniature channel box are $30 \mathrm{~mm} \times 30 \mathrm{~mm} \times 380 \mathrm{~mm}$, with a $1.25 \mathrm{~mm}$ wall thickness. The tube specimens have a prototypic PWR cladding diameter of $9.5 \mathrm{~mm}$, a wall thickness of $\sim 1 \mathrm{~mm}$, and a length of $380 \mathrm{~mm}$. Two aluminum internal supports, lower and upper, are stacked together on either end of the channel box and secured using a tie rod. The large features at the top and bottom of the support pieces ensure that the channel box remains centered inside the aluminum holder. Wave springs are placed between the channel box specimen and the supports to keep the channel box centered around the support pieces. The wave springs have minimal stiffness to allow the channel box to bow without applying any significant load, or stress on the channel box. Radial holes at the tops and bottoms of the tube specimens allow them to be secured to the internal supports using fasteners. The fasteners pass through the tube specimens and slots in the slotted pins, which are welded to the internal supports. This arrangement allows the tube specimens to bend and translate axially while maintaining their orientation inside the experiment. 


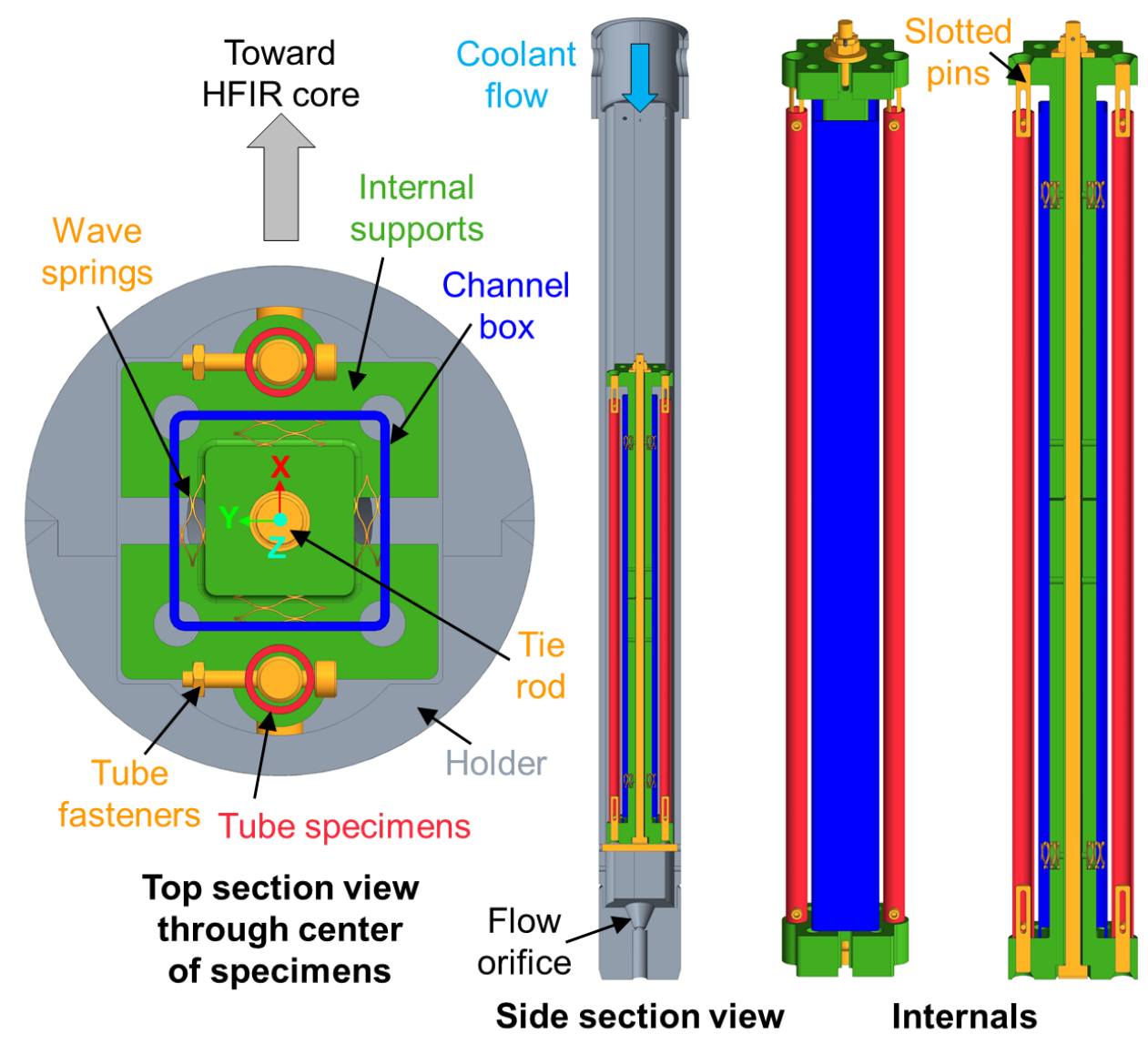

Figure 3. Design of the channel box experiment.

\section{COMPUTATIONAL METHODS}

\subsection{Neutronics Analysis}

Neutronics analyses were performed to determine the spatial variation in dose rate within the channel box specimen to provide input to the subsequent structural analyses. Analyses were performed using the MCNP5 software code package [30]. The MCNP calculations are based on existing fixed neutron source models of HFIR at beginning and end of cycle (BOC and EOC) with cycle 400 experimental loading [29]. Modifications were made to include the new experimental assembly inside VXF position 19, centered about the HFIR core midplane. The dose rates in the specimen were determined by tallying the neutron flux over a Cartesian mesh that was superimposed over the experiment and applying a weighting multiplier as follows [31]:

$$
\dot{d}=\frac{0.8}{2 E_{d}} \int_{0}^{\infty} \varphi(E) \sigma_{d}(E) d E .
$$

where $\dot{d}$ is the dose rate, $E_{d}$ is the average lattice displacement energy for $\mathrm{SiC}, \varphi(E)$ is the energydependent neutron flux, and $\sigma_{d}(E)$ is the energy-dependent displacement damage cross section for SiC. The factor of 0.8 is an equivalent displacement efficiency [32]. The lattice displacement energy for $\mathrm{SiC}$ is taken to be $30 \mathrm{eV}$, which is the average of $40 \mathrm{eV}$ for silicon and $20 \mathrm{eV}$ for carbon [33]. The integral quantity is assessed from the MCNP tally of neutron flux weighted by the displacement damage cross section from the standard MCNP cross section libraries. In the absence of variance reduction techniques, statistical noise 
is minimized by running $4 \times 10^{10}$ particle histories for each calculation, yielding uncertainties well within $2 \%$ across the entire calculation mesh.

\subsection{Structural Analysis}

A three-dimensional (3D) structural FEA was performed using the ANSYS software package to estimate the bowing in the channel box during irradiation. The experiment was modeled using a mesh size of $0.5 \mathrm{~mm}$ for the $\mathrm{X}$ and $\mathrm{Y}$ directions and a $2 \mathrm{~mm}$ mesh size for the $\mathrm{Z}$ direction (see Figure 4). The origin is at the centroid of the channel box specimen. Figure 4 also shows how the channel box was constrained in the structural analysis. Symmetry was assumed along the $\mathrm{XZ}$ plane so that the displacement in the Y direction $\left(U_{Y}\right)$ was constrained along this plane. Along the $X Y$ plane, displacement in the $Z$ direction $\left(U_{Z}\right)$ was constrained. Finally, the displacement in the $X$ direction $\left(U_{X}\right)$ was set equal to zero at a single point in the corner of the XY plane to prevent rigid body motion.

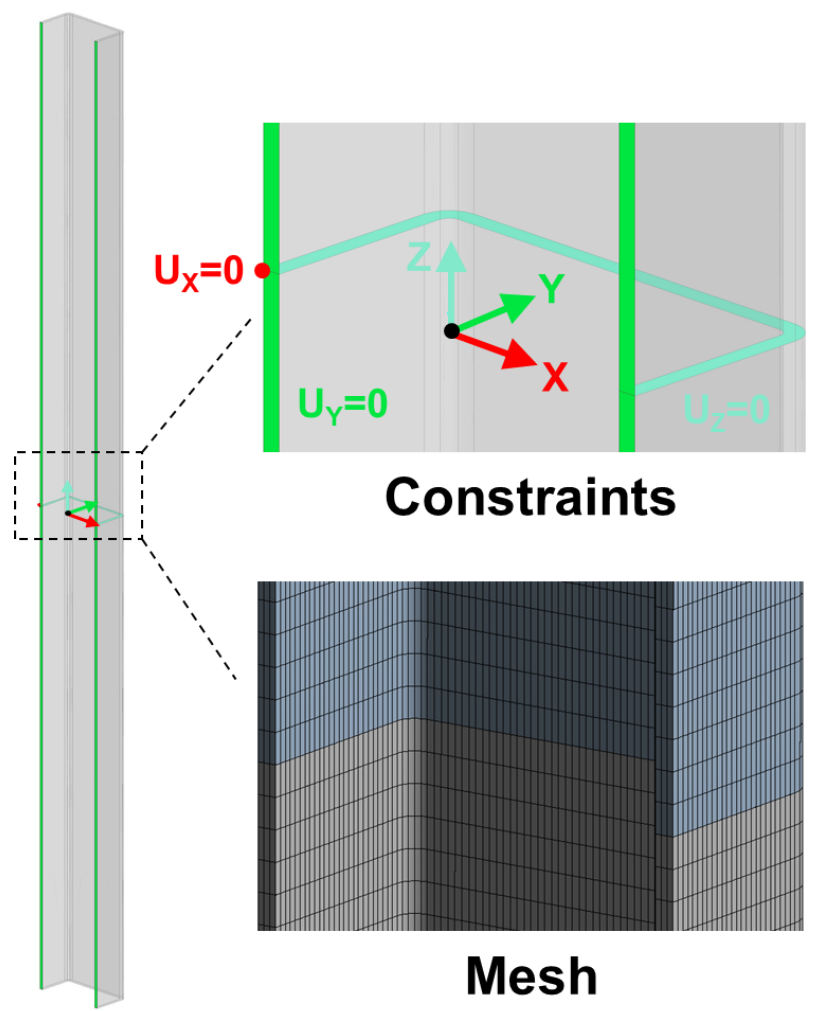

Figure 4. Structural model with displacement constraints and finite element mesh.

ANSYS has a built-in swelling model that requires the user to specify a spatially dependent neutron fluence and an equation to convert from fluence to linear swelling. For this work, the dose rates determined in the neutronics analysis (see previous section) were multiplied by the simulated irradiation time to give the total dose. Dose was converted to volumetric swelling using literature data from previous HFIR irradiation experiments performed at the same coolant temperatures [34]. The volumetric swelling was divided by a factor of 3 to convert to linear swelling (assumed isotropic swelling). The swelling vs. dose data obtained from the literature were fit to a power law to establish the dose-to-swelling model. The average specimen dose expected from one to two cycles of irradiation in a large VXF position in HFIR is expected be $\sim 0.025$ to $0.05 \mathrm{dpa}$ (see Section 5.1). This dose range is between two of the experimental data points obtained from the literature, providing increased confidence in the validity of the dose-to-swelling model. Instead of inputting a representative neutron fluence profile into ANSYS, the linear swelling profile was imported 
into ANSYS as a neutron fluence, and the fluence-to-swelling conversion was artificially set to unity. The structural analysis assumes only elastic deformation using an elastic modulus of $236 \mathrm{GPa}$. Previously reported values for nuclear-grade $\mathrm{SiC} / \mathrm{SiC}$ composites fabricated using chemical vapor infiltration were in the range of 200-280 GPa [1]. The calculation assumed a constant temperature of $60^{\circ} \mathrm{C}$. The effects of creep and pseudo-ductility due to microcracking were ignored. Creep was previously shown to have little impact on radiation-induced bowing [26], and the stresses are calculated to be well below typical proportional limit stresses for $\mathrm{SiC} / \mathrm{SiC}$ composites (see Section 5.2). Simulations were performed for one and two HFIR irradiation cycles, each assumed to have a duration of 25 days.

\section{EXPERIMENTAL METHODS}

\subsection{Specimen Fabrication}

The $\mathrm{SiC} / \mathrm{SiC}$ composite channel box was fabricated by GA. The channel box uses Hi-Nicalon Type-S SiC fibers with a nominally $150 \mathrm{~nm}$ thick pyrolytic carbon interphase surrounded by a $\mathrm{SiC}$ matrix formed by chemical vapor infiltration and a thin outer layer formed using chemical vapor deposition. The fiber architecture used two plies with a $\pm 71^{\circ}$ braiding angle. The nominal fiber volume fraction was $30-40 \%$. The average macroscopic density was determined to be $2.5 \mathrm{~g} / \mathrm{cm}^{3}$. More details regarding GA's fabrication process can be found in a previous publication [10]. Figure 5 shows a picture of the channel box, 2D radiographs, and a 3D reconstruction of a section of a similar channel box obtained using x-ray computed tomography.
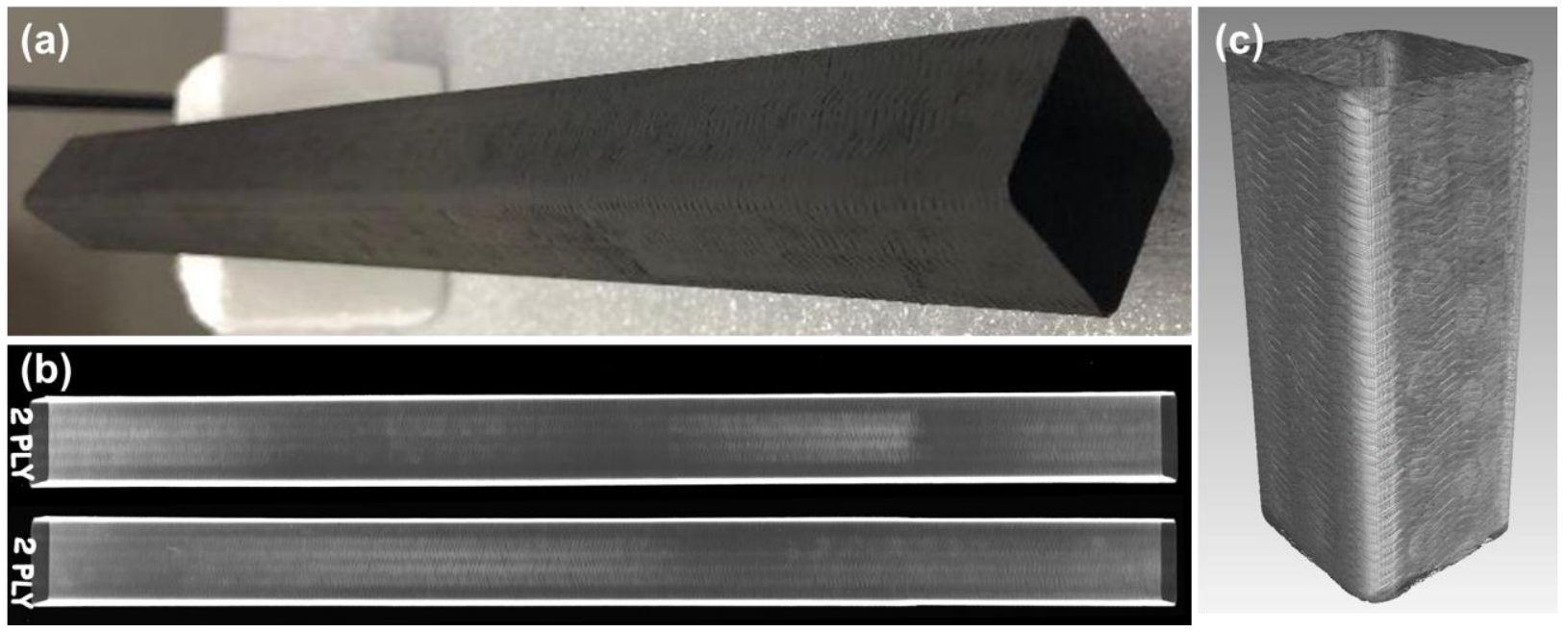

Figure 5. (a) Picture of the channel box, (b) two-dimensional radiographs, and (c) a threedimensional reconstruction of a section of a similar channel box obtained using x-ray computed tomography.

\subsection{Specimen Engraving}

Laser engraving was performed to provide marks for determining local displacements after irradiation. Figure 6 shows pictures of the specimen after engraving, including a processed image of a single mark. Each face of the channel box was engraved with three rows of " $X$ " marks separated by $\sim 25 \mathrm{~mm}$. Lines were engraved in the horizontal and vertical directions between marks and each mark was surrounded by an engraved circle. These features will help locate the fine markings on the rough surface of the channel box, especially after irradiation, when the measurement procedure may be more challenging owing to 
radiological concerns. The engraving was performed using an ACSYS PIRANHA I FL20S laser marking system to achieve a line width of approximately $30 \mu \mathrm{m}$. Such a fine line width is necessary to accurately locate the center of each mark to determine post-irradiation displacements.

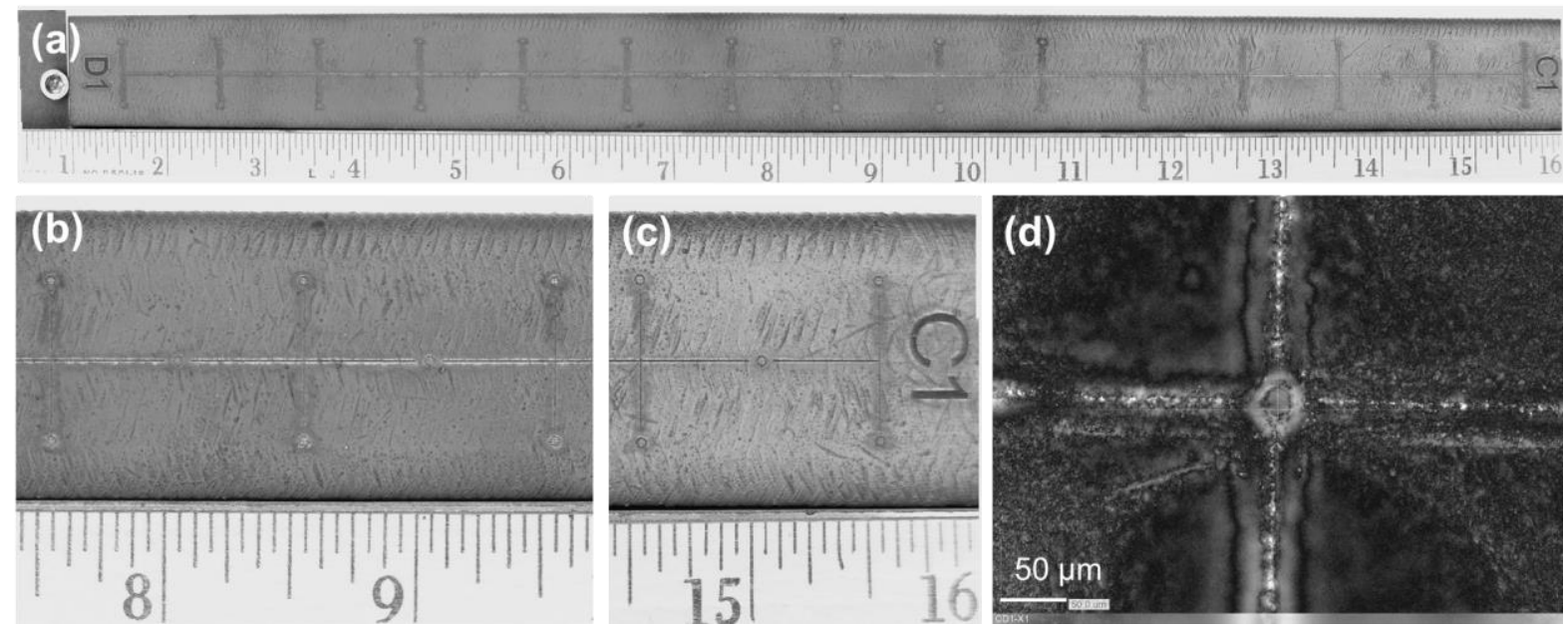

Figure 6. Photograph (a) of the engraved channel box specimen; (b, c) closer views of the engraved markers and (d) a processed image of a single marker.

\subsection{Specimen Characterization}

Specimens were first dimensionally inspected using micrometers and a height gauge for the length. Figure 7 summarizes the dimensional measurements. Three length measurements were made on each of the four faces of the channel box for a total of 12 measurements. These dimensions are denoted $\mathrm{L}_{\mathrm{ia}}, \mathrm{L}_{\mathrm{ib}}$, and $\mathrm{L}_{\mathrm{ic}}$, where " $\mathrm{i}$ " is the engraved index following the letter " $C$ " or " $D$." The width $\left(\mathrm{W}_{\mathrm{j}}\right)$ and depth $\left(\mathrm{D}_{\mathrm{j}}\right)$ were measured at five equally spaced axial locations ( $\mathrm{j}$ ) along the length of the channel box. Wall thicknesses were measured on all four faces at both the top and bottom of the channel box and are denoted $\mathrm{T}_{\mathrm{Ci}}$ and $\mathrm{T}_{\mathrm{Di}}$, respectively. Mass was measured to estimate the specimen density from the volume that was estimated using the volume displacement method. 


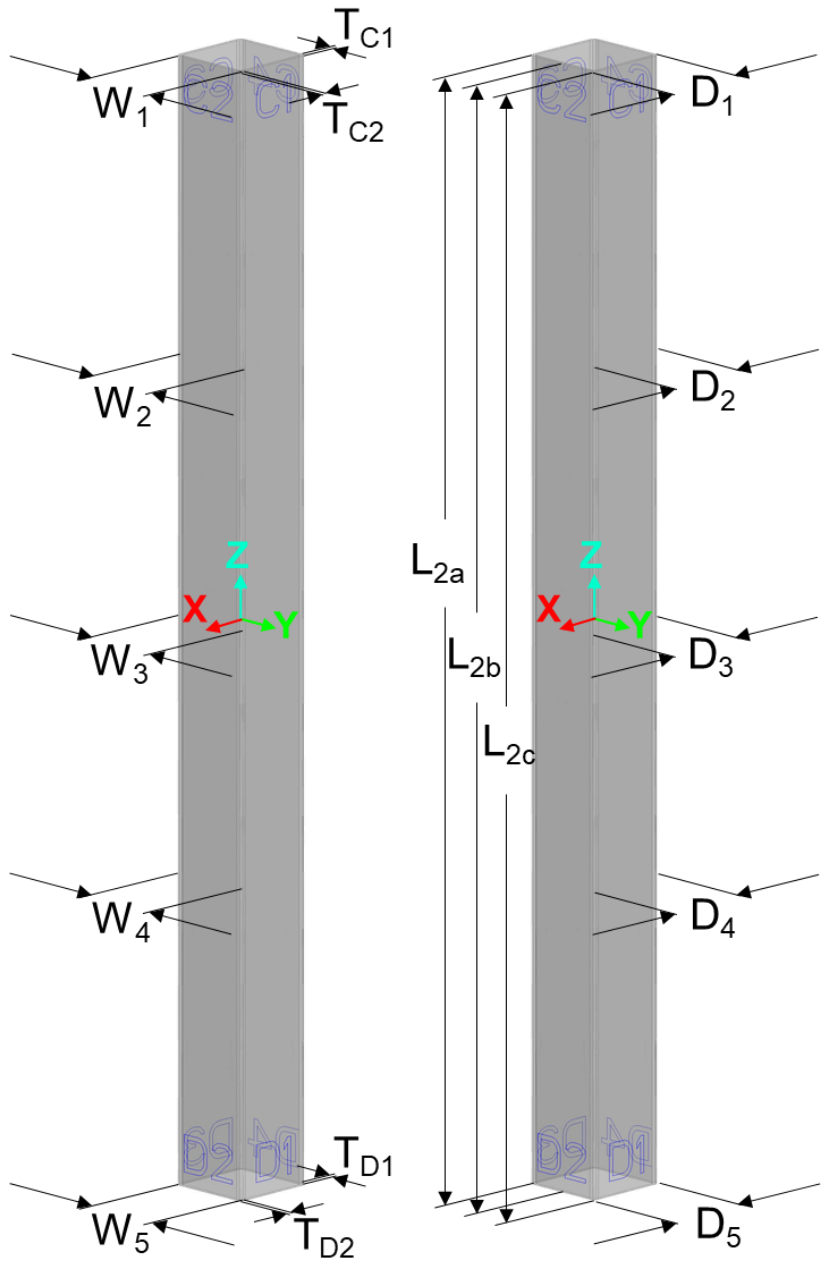

Figure 7. Labeling for dimensional inspection.

A custom profilometry system (Figure 8) was developed to more accurately characterize the channel box profile before and after irradiation. The system uses a Keyence LS-9030MR optical micrometer and a remotely-controlled, three-dimensional stage. The channel box was placed on its side on top of a polished and precisely machined stainless steel block. The optical profilometer was fixed to the stage adjacent to the specimen. The profilometer used edge detection to identify the top surface of the specimen and tracked the variation in the profile of this surface as the stage translated along the specimen's length. All profilometry data were post-processed using coordinate transformations so that the first and last points-corresponding to the top and bottom of the specimen, respectively_were coplanar, even if the specimen or the stage was not perfectly flat.

The profilometry stage also includes a mount for a digital microscope (Dino-Lite AF4115ZT for low magnification and Dino-Lite AM73515MT8A for high magnification) that looks down on the top of the specimen. The combination of the microscope (magnification $>900 \mathrm{X}$ ) and the stage allowed for precise determination of the distance between the engraved markers. The microscope was used to identify the center of each marker, and the $\mathrm{X}, \mathrm{Y}$, and $\mathrm{Z}$ coordinates from the stage were recorded for each marker. Figure 8a is labelled with face $\mathrm{i}=2$ facing up, which orients the surface normal to the $\mathrm{X}$ direction. Image analysis can be performed to more precisely identify the center of the marker relative to the center of the image. The displacement measurements are expected to be accurate to within $<10 \mu \mathrm{m}$, which is limited by the image 
analysis rather than the accuracy of the stage $( \pm 1 \mu \mathrm{m}) . \mathrm{A} \pm 10 \mu \mathrm{m}$ displacement resolution corresponds to a linear strain resolution of $\pm 0.01 \%$.

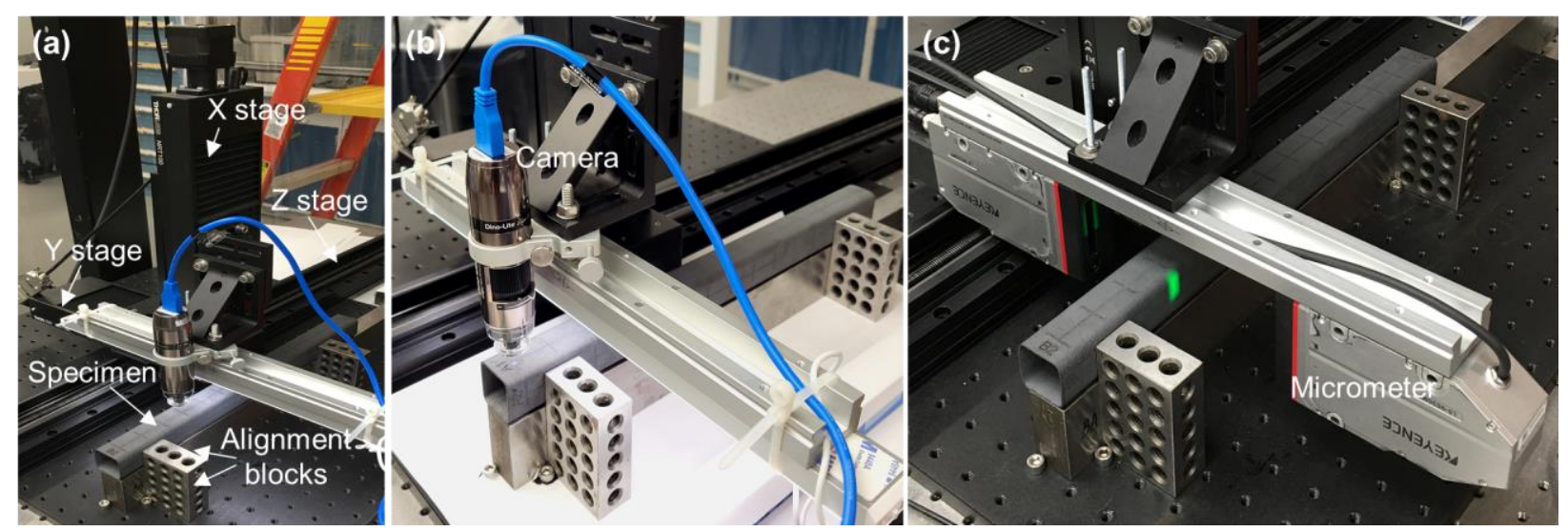

Figure 8. Pictures showing the translation stage that is used for both $(a, b)$ local strain measurements with a digital microscope and (c) bowing measurements with an optical profilometer.

\section{RESULTS}

\subsection{Neutronics Analysis}

The spatially dependent dose rates in the channel box specimen are summarized in Figure 9. Because of the stochastic nature of the Monte Carlo calculations, the uncertainties in the calculated dose rates create artifacts that prevent a smooth spatial distribution even when $4 \times 10^{10}$ source particles are used. These artifacts manifest as non-physical stresses in the structural analyses. To prevent these artifacts, the dose rate distributions were fit to an equation with the following form:

$$
\dot{d}(\mathrm{X}, \mathrm{Z})=\dot{d}_{\max } \exp \left[\frac{\mathrm{X}-\max \{\mathrm{X}\}}{\gamma_{X}}\right] \exp \left[-\left(\frac{\mathrm{Z}}{\gamma_{Z}}\right)^{2}\right],
$$

where $\dot{d}_{\max }$ is the maximum simulated dose rate, $\gamma_{X}$ determines the reduction in $\dot{d}$ with decreasing $\mathrm{X}$, $\max \{\mathrm{X}\}=15 \mathrm{~mm}$ is the maximum simulated value of $\mathrm{X}$, and $\gamma_{Z}$ determines the spatial profile of $\dot{d}$ with respect to Z. Because of symmetry, the spatial dependence of $\dot{d}$ on Y is not significant. Figure 9a and Figure $9 \mathrm{~b}$ show BOC and EOC dose rates, respectively, vs. Z showing simulated data (solid lines) and fits (dashed lines). The fit parameters are summarized in Table 1, including the goodness-of-fit parameters $R^{2}$, which show that the data are well-represented by the fits. Figure 9c shows 3D dose rates at BOC (EOC profiles look similar) at $Y=0$ vs. $X$ and $Z$. Figure $9 \mathrm{~d}$ shows the dose rates and the spatial distributions of volumetric swelling in $\mathrm{SiC}$ at $\mathrm{Y}=0, \mathrm{Z}=0$ vs. $\mathrm{X}$ determined using the fit after one and two HFIR cycles. The $\mathrm{Y}$ location for Figure 9d was arbitrarily chosen because there is no significant variation in the calculated dose rate with respect to $\mathrm{Y}$. The calculations predict a $\sim 35 \%$ reduction in dose rate from the front face (facing toward the core) to the back face (facing away from the core) of the $30 \mathrm{~mm}$ square channel box specimen. This dose rate variation is similar to the $25-29 \%$ variation in fast neutron flux across approximately a dozen fresh channels in typical BWRs [23]. The magnitudes of the calculated dose rates are on the order of $10^{-5} \mathrm{dpa} / \mathrm{hr}$, which are about an order of magnitude lower than those in a typical BWR. As shown in Figure 9d, the difference in volumetric swelling across the channel box increases significantly between cycles 1 and 2 . 

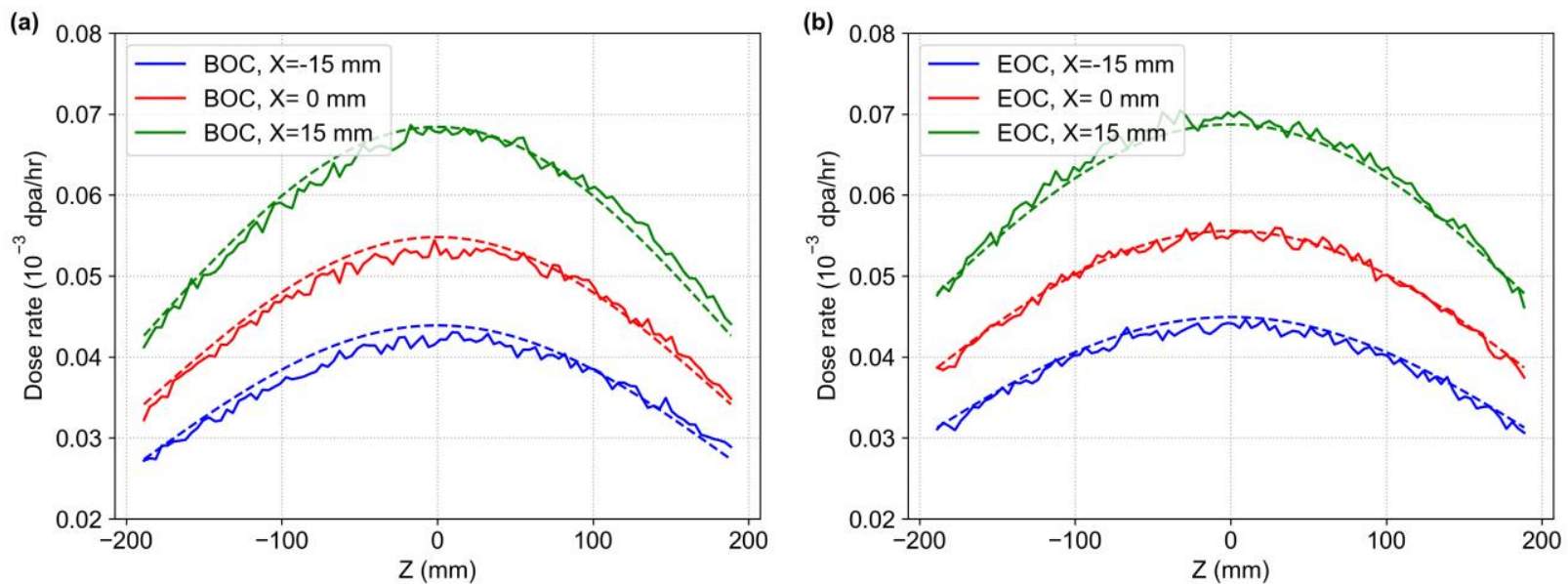

(c)
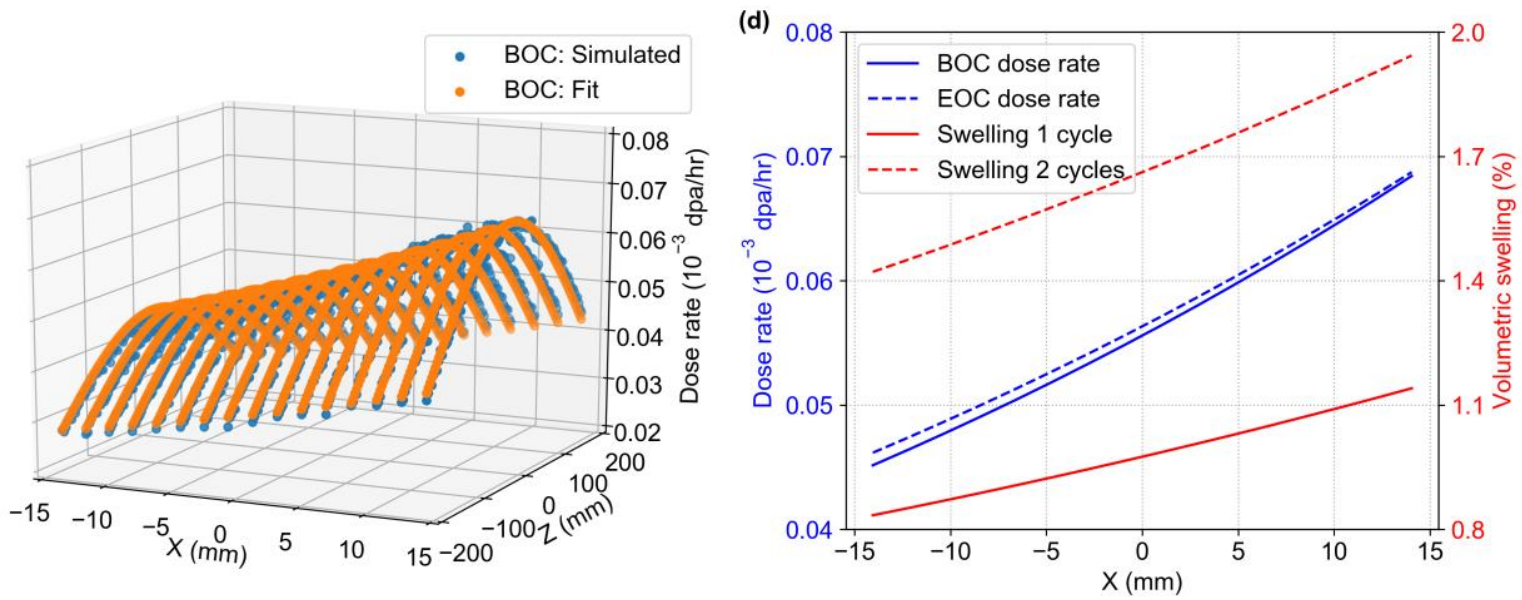

Figure 9. (a, b) BOC and EOC dose rates, respectively, at $\mathrm{Y}=0$ and various $\mathrm{X}$ vs. $\mathrm{Z}$ showing simulated data (solid lines) and fits (dashed lines); (c) 3D BOC dose rates at $\mathrm{Y}=0 \mathrm{vs.} \mathrm{X}$ and $\mathrm{Z}$ showing simulated data and fits; (d) dose rate and volumetric swelling at $Y=0, Z=0$ vs. $X$ determined using the fit after one and two HFIR cycles. The center of the HFIR core is in the positive $\mathrm{X}$ direction.

Table 1. Fitting parameters for the simulated dose rate distributions.

\begin{tabular}{ccccc}
\hline Time & $\begin{array}{c}\dot{\mathrm{d}}_{\max } \\
(\mathrm{dpa} / \text { hour })\end{array}$ & $\begin{array}{c}\gamma_{\mathrm{X}} \\
(\mathrm{mm})\end{array}$ & $\begin{array}{c}\gamma_{\mathrm{Z}} \\
(\mathrm{mm})\end{array}$ & $\mathrm{R}^{2}$ \\
\hline BOC & $6.84 \times 10^{-5}$ & 67.6 & 274 & 0.984 \\
\hline EOC & $6.87 \times 10^{-5}$ & 70.4 & 313 & 0.990 \\
\hline
\end{tabular}

\subsection{Structural Analysis}

The 3D spatial distributions of volumetric swelling were input to structural finite element simulations. Figure 10 shows contour plots of the predicted lateral displacement $\mathrm{U}_{\mathrm{X}}$ (in meters), as well as the normal stresses $\sigma_{\mathrm{X}}, \sigma_{\mathrm{Y}}$, and $\sigma_{\mathrm{Z}}$ (in $\mathrm{Pa}$ ), after two cycles of irradiation. The visual deformations are artificially magnified by a factor of $10 \mathrm{in}$ the displacement plot and a factor of 50 in the stress plots, and the undeformed structure is also shown as a wire frame. The stress distributions after one cycle are similar except with lower magnitudes. All stresses are relatively low with magnitudes of less than $13 \mathrm{MPa}$. In the Y direction (Figure 
10b), the stresses transition from tension to compression through the thickness of the X-normal faces and are essentially neutral on the Y-normal faces. Similarly, the normal X stresses are neutral on the X-normal surfaces but transition from tension to compression moving in the $\mathrm{X}$ direction along the $\mathrm{Y}$-normal surfaces. The $\mathrm{Z}$-normal stresses become more compressive moving in the positive $\mathrm{X}$ direction along the $\mathrm{X}$-normal faces. On the $\mathrm{Y}$-normal faces, the $\mathrm{Z}$-normal stresses have maximum tension in the center of the faces $(\mathrm{X}=0)$ and decrease moving in the positive and negative $\mathrm{X}$ direction.

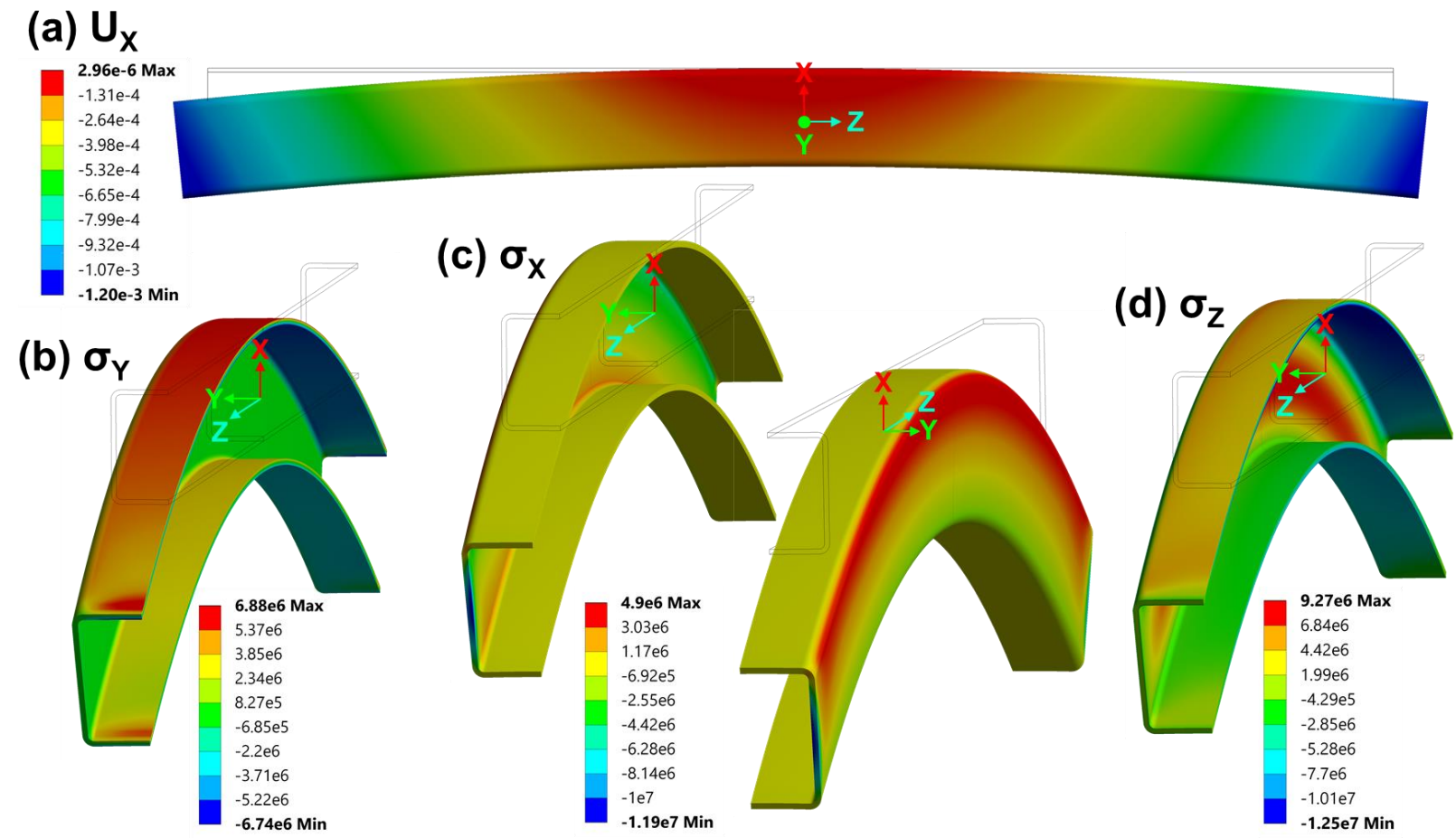

Figure 10. Simulated channel box bowing after two HFIR cycles showing (a) lateral displacement $\mathrm{U}_{\mathrm{X}}$ (in $\mathrm{m}$ ), with visual deformations artificially scaled by a factor of 10, and (b, c, d) normal stresses (in Pa) with visual deformations artificially scaled by a factor of $\mathbf{5 0}$.

Figure 11 shows $U_{X}$ as a function of $Z$, with the number of cycles as a parameter. Results were obtained using FEA and analytical Eqs. (1) and (2). The analytical equations used swelling data from Figure 9d evaluated at $\mathrm{Z}=0 \mathrm{~mm}$ to determine $\left(\frac{d V}{V}\right)_{\text {diff }}$. The fact that the FEA results are essentially identical to the analytical results shows that the bowing is primarily dictated by differential swelling at $\mathrm{Z}=0 \mathrm{~mm}$ and that the axial variation in dose rate does not have a significant effect. The lateral bowing shown in Figure 11 is defined as the maximum lateral displacement for all nodes at a given $\mathrm{Z}$ position relative to the maximum lateral displacement at $\mathrm{Z}=0 \mathrm{~mm}$. In this way, the lateral bowing compensates for the swelling of the channel box in the $\mathrm{X}$ direction. The lateral displacements in Figure 10 include the effects of bowing and swelling in the $\mathrm{X}$ direction. This explains why the maximum absolute value of $U_{X}$ in Figure $10(1.2 \mathrm{~mm})$ is slightly larger than that in Figure $11(1.02 \mathrm{~mm})$ after two cycles of irradiation. 


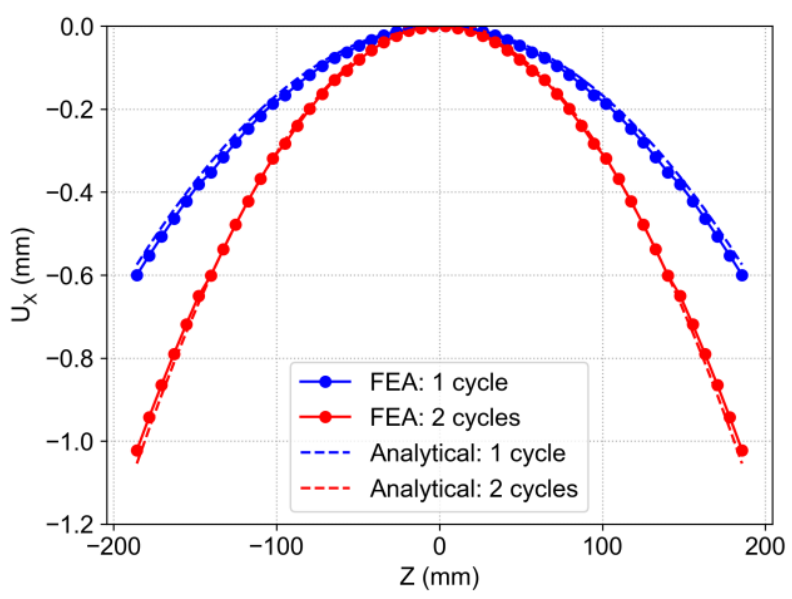

Figure 11. Lateral bowing profiles determined using FEA and analytical equations after 1 and 2 HFIR cycles.

\subsection{Pre-Irradiation Characterization}

\subsubsection{Dimensional Inspection}

The channel box was first dimensionally inspected to provide a reference to which post-irradiation measurements can be compared. Table 2 summarizes the dimensional inspection using the notation in Figure 7.

Table 2. Summary of pre-irradiation dimensional inspections.

\begin{tabular}{cccccc}
\hline Mass $(\mathrm{g})$ & 100.2936 & & & & \\
\hline & $\mathrm{i}=1$ & $\mathrm{i}=2$ & $\mathrm{i}=3$ & $\mathrm{i}=4$ & \\
\hline $\mathrm{L}_{\mathrm{ia}}(\mathrm{mm})$ & 382.226 & 382.122 & 382.484 & 382.920 & \\
\hline $\mathrm{L}_{\mathrm{ib}}(\mathrm{mm})$ & 382.480 & 382.105 & 382.386 & 382.698 & \\
\hline $\mathrm{L}_{\mathrm{ic}}(\mathrm{mm})$ & 382.686 & 382.089 & 382.341 & 382.680 & \\
\hline $\mathrm{T}_{\mathrm{Ci}}(\mathrm{mm})$ & 1.188 & 1.229 & 1.152 & 1.288 & \\
\hline $\mathrm{T}_{\mathrm{Di}}(\mathrm{mm})$ & 1.327 & 1.028 & 1.380 & 1.191 & \\
\hline & $\mathrm{j}=1$ & $\mathrm{j}=2$ & $\mathrm{j}=3$ & $\mathrm{j}=4$ & $\mathrm{j}=5$ \\
\hline $\mathrm{W}_{\mathrm{j}}(\mathrm{mm})$ & 29.614 & 29.418 & 29.705 & 29.606 & 29.295 \\
\hline $\mathrm{D}_{\mathrm{j}}(\mathrm{mm})$ & 29.391 & 29.846 & 29.169 & 29.123 & 30.053 \\
\hline
\end{tabular}

\subsubsection{Profilometry}

Profilometry measurements were performed to compare the detailed specimen profiles before and after irradiation. Before the channel box specimen was measured, two calibration measurements were performed. First, a nominally straight stainless steel bar was scanned to ensure that the system did not introduce significant artifacts into the measurements. After scanning the bar in one direction, the bar was reversed and rescanned. The maximum profile variation of the stainless steel bar was measured to be 3-4 $\mu \mathrm{m}$ using a dial indicator. Next, an aluminum square $(31.75 \mathrm{~mm}$ width) channel specimen was procured and bent around a mandrel to introduce a nominal bow of $0.76 \mathrm{~mm}$. Figure 12 shows the profilometry measurements for these scans. Figure 12a shows a maximum profile deviation in the range of $\sim 28 \mu \mathrm{m}$. Because the forward and reversed scans show similar profiles, the $28 \mu \mathrm{m}$ profile variations are likely 
caused by slight bowing of the track along which the profilometer travels. However, the $28 \mu \mathrm{m}$ profile variation is much less than the expected radiation-induced bowing (see Figure 11). Furthermore, this variation would be present in both pre-irradiation and post-irradiation measurements. Therefore, the effects of the variation in the profilometer track can be compensated by subtracting the pre-irradiation surface profile from the post-irradiation profile.

Figure $12 \mathrm{~b}$ shows that in the planes of the intentional bow (" $1 \mathrm{~L}$ to $1 \mathrm{R}$ " and " $3 \mathrm{~L}$ to $3 \mathrm{R}$ "), the measured bow is consistent with the nominal value of $0.76 \mathrm{~mm}$. Furthermore, the system clearly shows that the surface labeled " $3 \mathrm{~L}$ to $3 \mathrm{R}$ " has more localized deformation near the center of the specimen, likely because the mandrel contacted the specimen on this face during the bending operations. The measurements in the " $2 \mathrm{~L}$ to $2 \mathrm{R}$ " and " $4 \mathrm{~L}$ to $4 \mathrm{R}$ " planes do not show significant bowing, as expected. The large profile variations in the " $2 \mathrm{~L}$ to $2 \mathrm{R}$ " plane are caused by tape that was placed on this surface to identify the specimen.
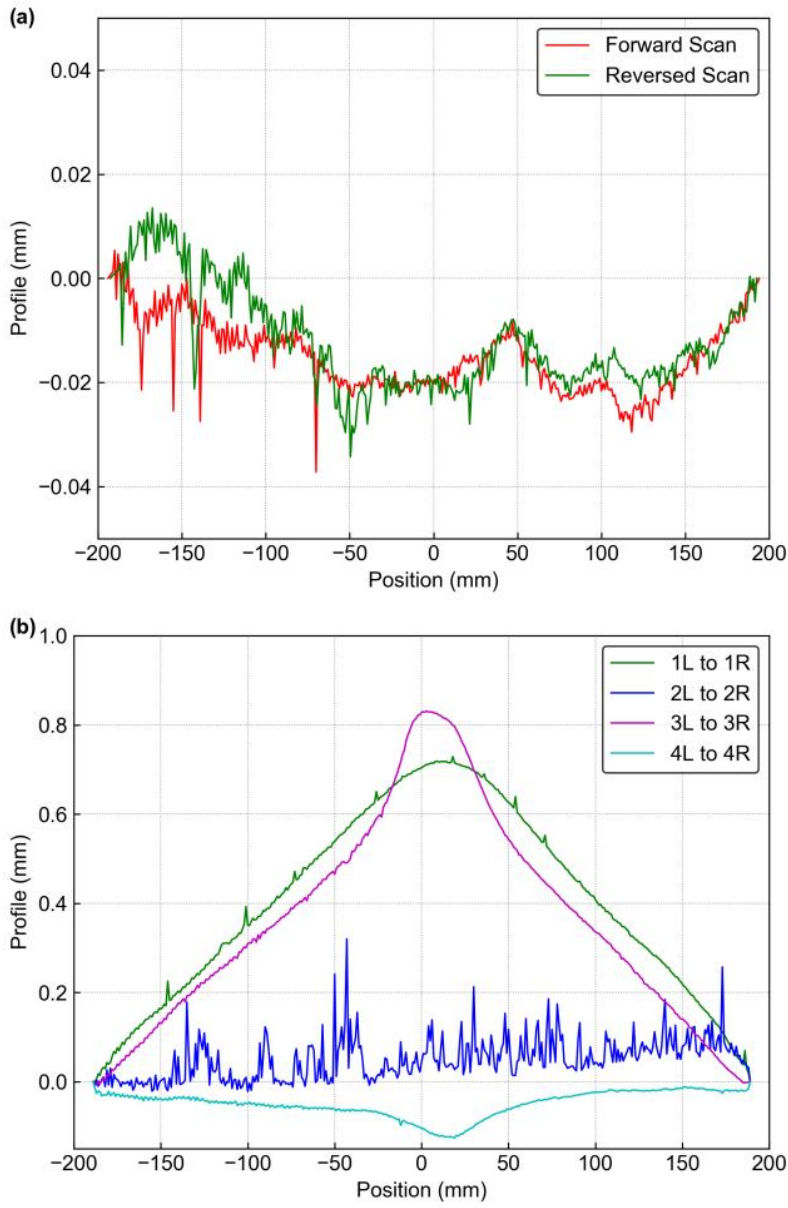

\section{Figure 12. Profilometry calibration scans of (a) a straight stainless steel bar and (b) a dummy aluminum square channel with a nominally $0.76 \mathrm{~mm}$ bow introduced by bending around a mandrel.}

Figure 13 shows the profilometry measurements for the channel box specimen. The position data (Z, horizontal axis) are reversed in these plots so that following the profiles from left to right in Figure 13 is equivalent to following the specimen profiles from top to bottom (i.e., from engraved markers "Ci" to "Di"). The roughness of the composite specimen's surfaces is evident in the specimen profiles. Therefore, a third-order Savitzky-Golay filter was used with a 15-point window (15 $\mathrm{mm}$ in the $\mathrm{Z}$ direction) to filter 
the effects of the specimen's surface roughness. Figure 13a shows the measured data (solid lines) and the filtered data (dashed lines). Because the filtered data are difficult to see, Figure 13b shows only the filtered data. The parallel C1 D1 (red lines) and C3 D3 (blue lines) faces generally show a positive bow with a maximum value of $0.67 \mathrm{~mm}$ on the $\mathrm{C} 3 \mathrm{D} 3$ face. Both faces show a sharp decrease in the profile near $Z=105 \mathrm{~mm}$. This decrease is consistent with the specimen width decreasing from $W_{1}$ to $W_{2}$ and then increasing from $W_{2}$ to $W_{3}$ (see Table 2). The differences in the C1 D1 and C3 D3 profiles for $Z<90 \mathrm{~mm}$ must be a result of features that are present on one face and not on the other. Similar differences can be observed between the C2 D2 and C4 D4 faces, although some common features can be observed that could be attributed to bending or bowing. Examples include the decreases observed from $\mathrm{Z}=160$ to $189 \mathrm{~mm}$ and the increase and plateau observed from $\mathrm{Z}=-70$ to $46 \mathrm{~mm}$.
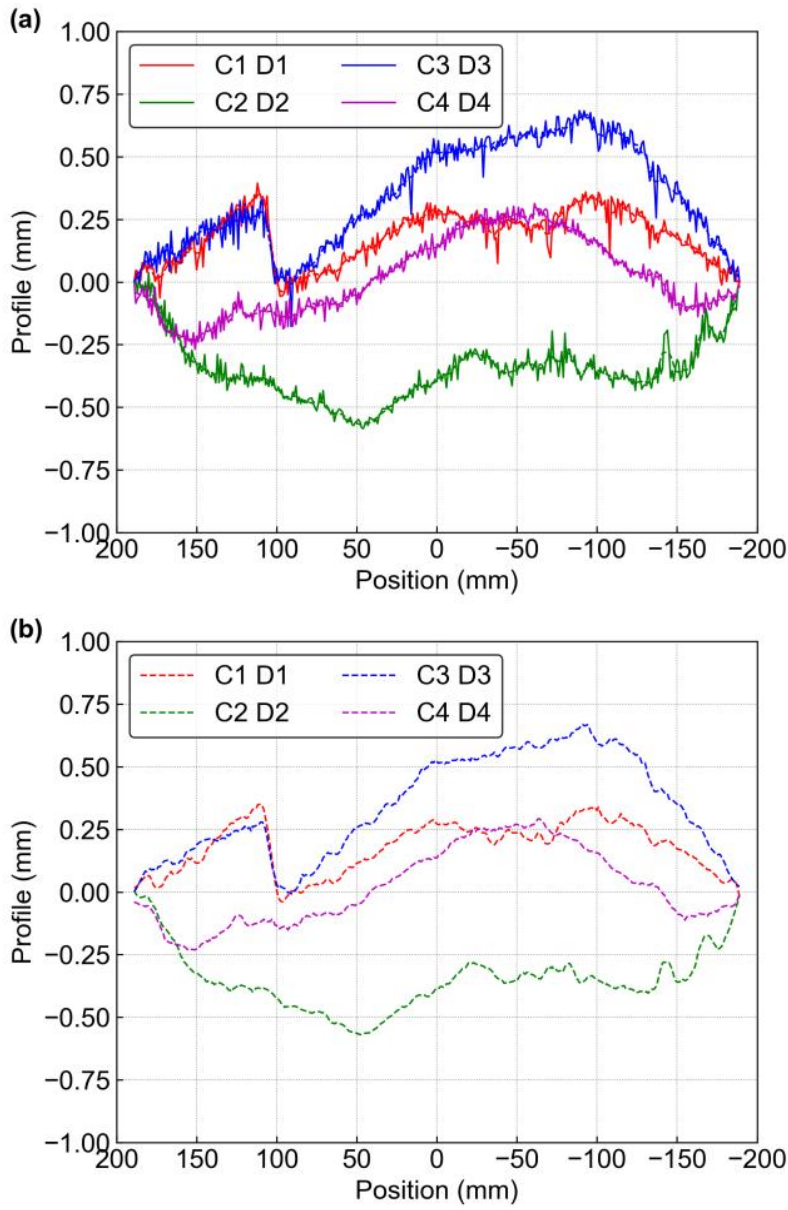

Figure 13. Profile measurements for the channel box specimen showing (a) measured data (solid lines) and filtered data (dashed lines), and (b) only the filtered data.

\subsubsection{Marker Spacing for Local Strain Mapping}

Figure 14 shows the locations that were measured for each marker before irradiation. The individual marker locations are summarized in the Appendix. For reference, Figure 14a shows the configuration for the various specimen faces. The dashed black lines in Figure 14b outline the outer surface of each face. The single red marker on face C3 D3 is questionable because one coordinate is thought to have been transposed during the recording process. The corrected coordinate is shown; however, because it is not certain whether a transposing error occurred, this marker has been flagged. Additional image analysis is currently under way to increase the precision of the marker spacing measurements by determining the 
deviation of the centroid of each marker relative to the center of each image (see Figure $6 \mathrm{~d}$ for an example).

(a)

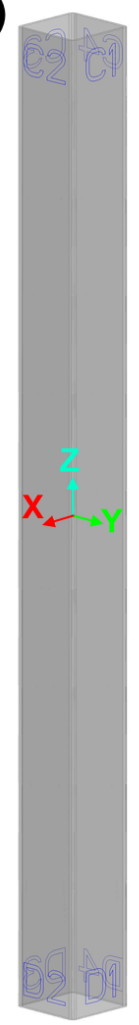

(b)
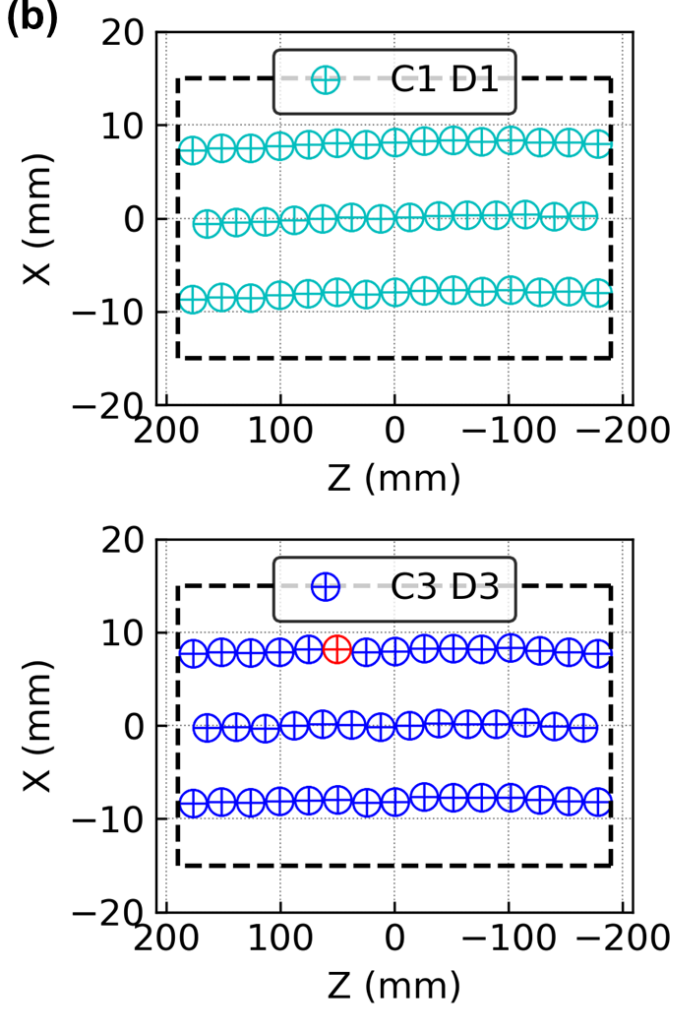
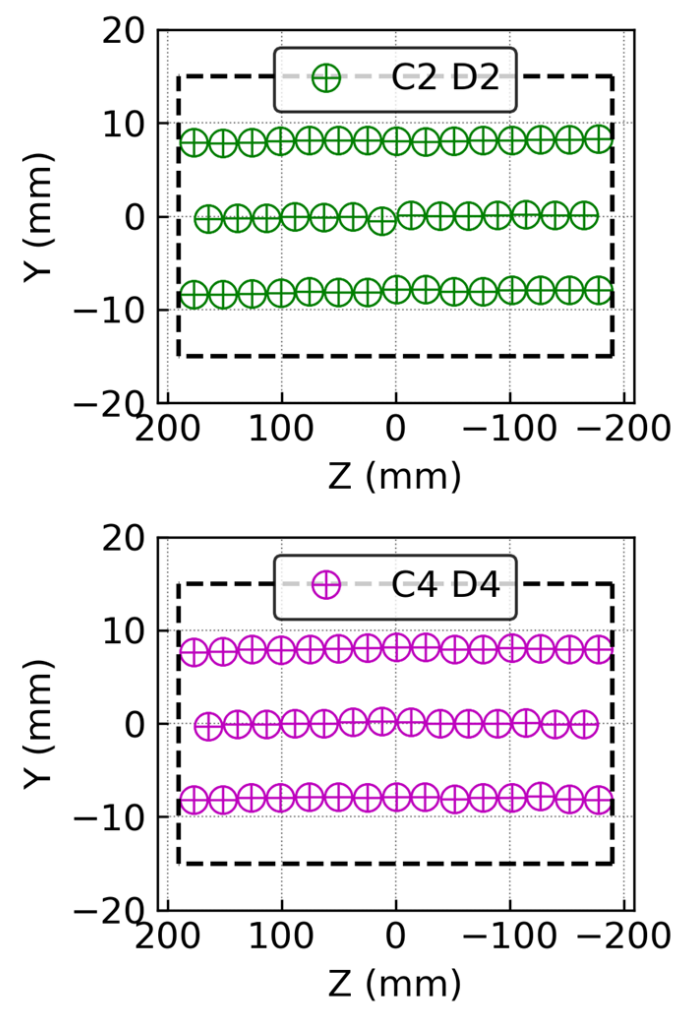

Figure 14. Measured engraved marker locations showing (a) the configuration for the various specimen faces and (b) the measured marker locations. The outer surfaces of each face are shown as dashed black lines. The single red marker on face C3 D3 is questionable because one coordinate is thought to have been transposed during the recording process. Because this is not certain, this marker has been flagged.

\subsection{Experiment Assembly}

The first step in the experiment assembly involved welding the outer aluminum holder. Figure 15 shows pictures of the holder components before ( $a, b, c)$ and after (d, e, f) assembly. The two halves of the holder body were welded in two places at three axial heights. Three of the weld locations on one side of the holder that were later filled can be seen in Figure 15c. The bottom orifice was welded to the bottom of the holder body halves. A top ring was also welded to provide additional structural support to prevent the holder from splitting at its top. Finally, a rod was inserted through both holder halves and welded in place to provide a support upon which the internal components rested. The orifice and welded rod are visible in Figure 15e. 


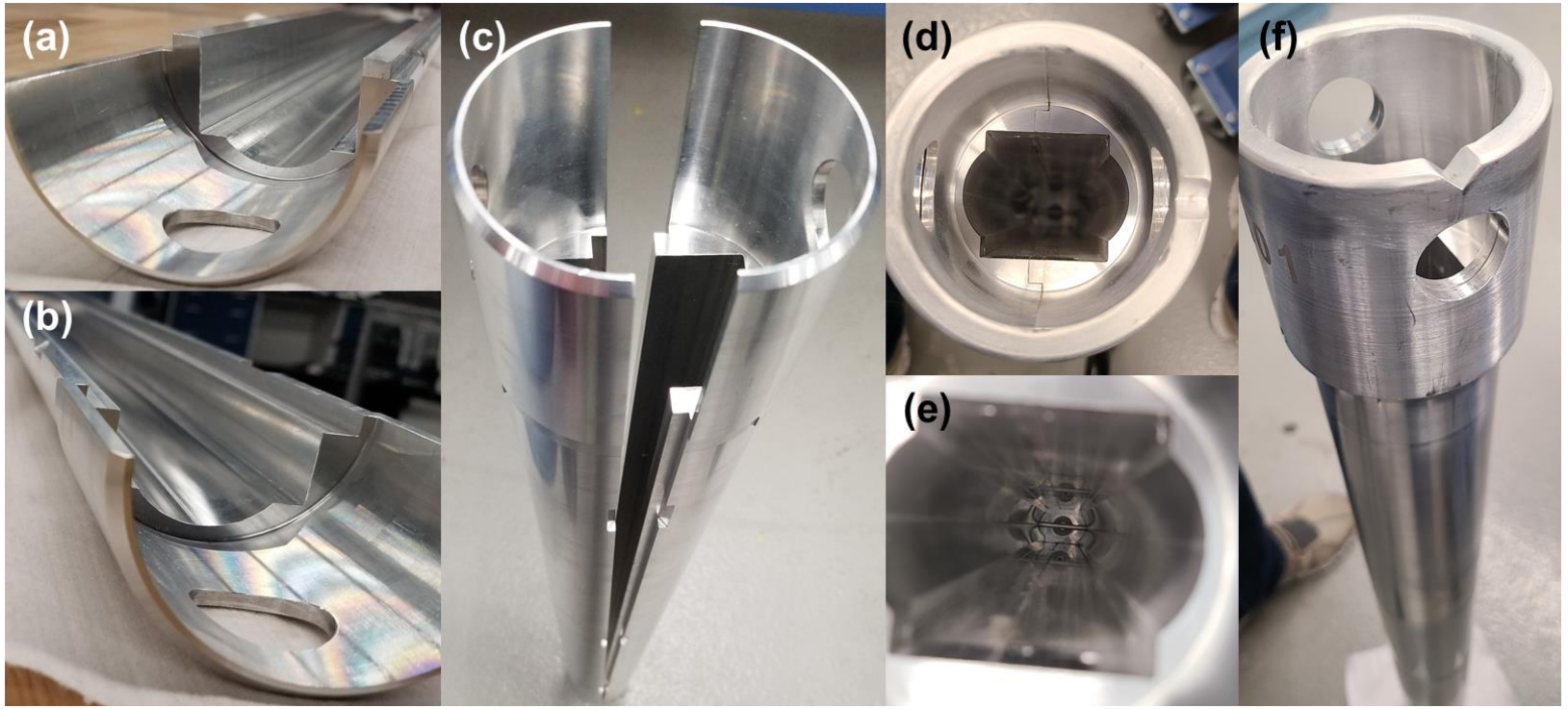

Figure 15. Photographs of the holder assembly.

Next, the internal components were assembled. Figure 16 shows the parts layout and Figure 17 shows the assembly process. The slotted pins were welded to the bases of the internal supports and wave springs were inserted into the matching holes in the sides of the internal supports. The channel box specimen was placed around one of the two internal supports as the wave springs were compressed. The tube specimens were placed over each of the slotted pins that were welded to the same internal support and were then secured using fasteners. This assembly was then lowered onto the second internal support while aligning the tube specimens and the channel box. Fasteners were secured to the opposite ends of the tube specimens, and the tie rod was inserted through both internal supports and secured at the top using a lock nut and cotter pin. The entire internal assembly was then lowered into the holder until it came to rest on the welded rod. 


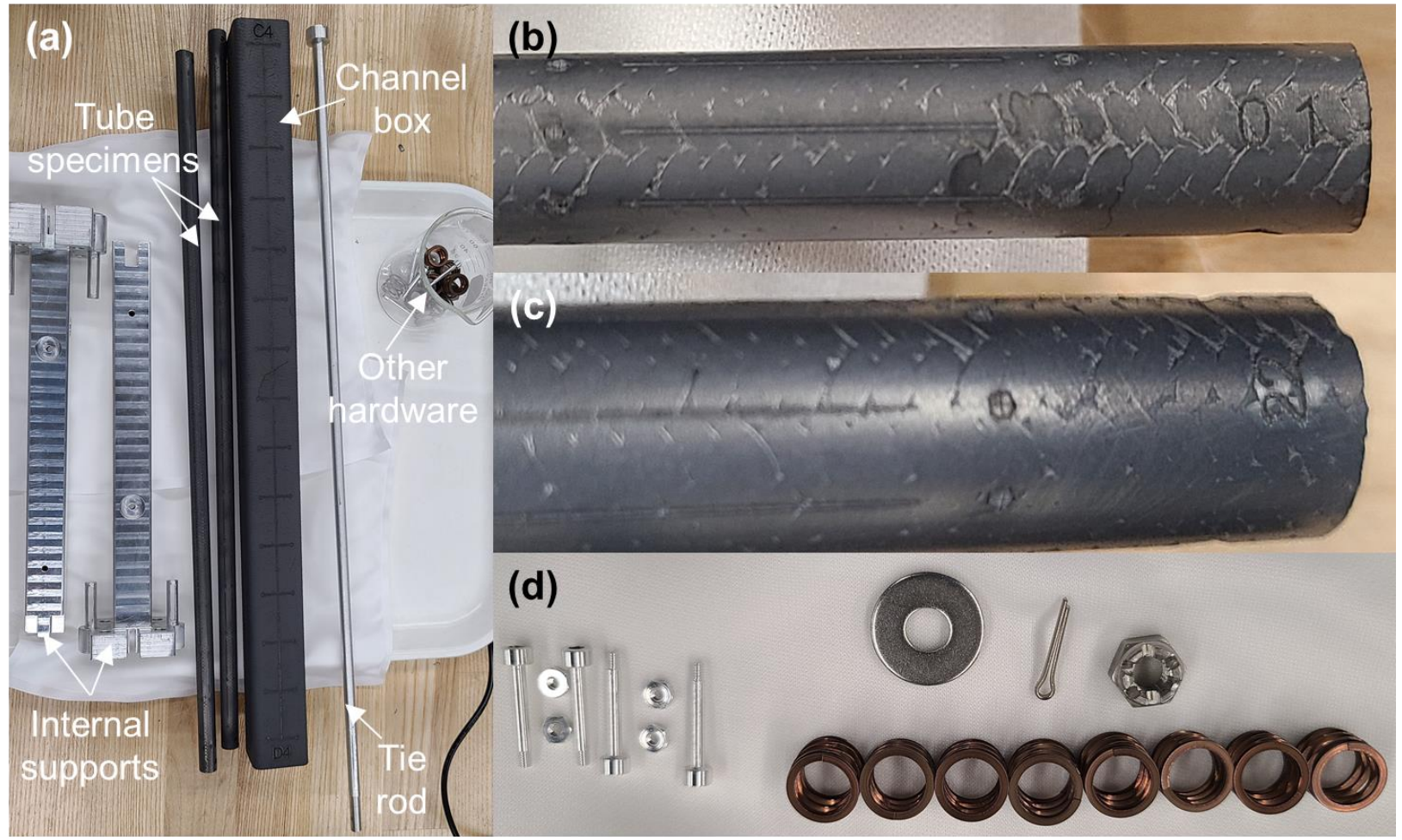

Figure 16. Photographs of the internal experiment components.

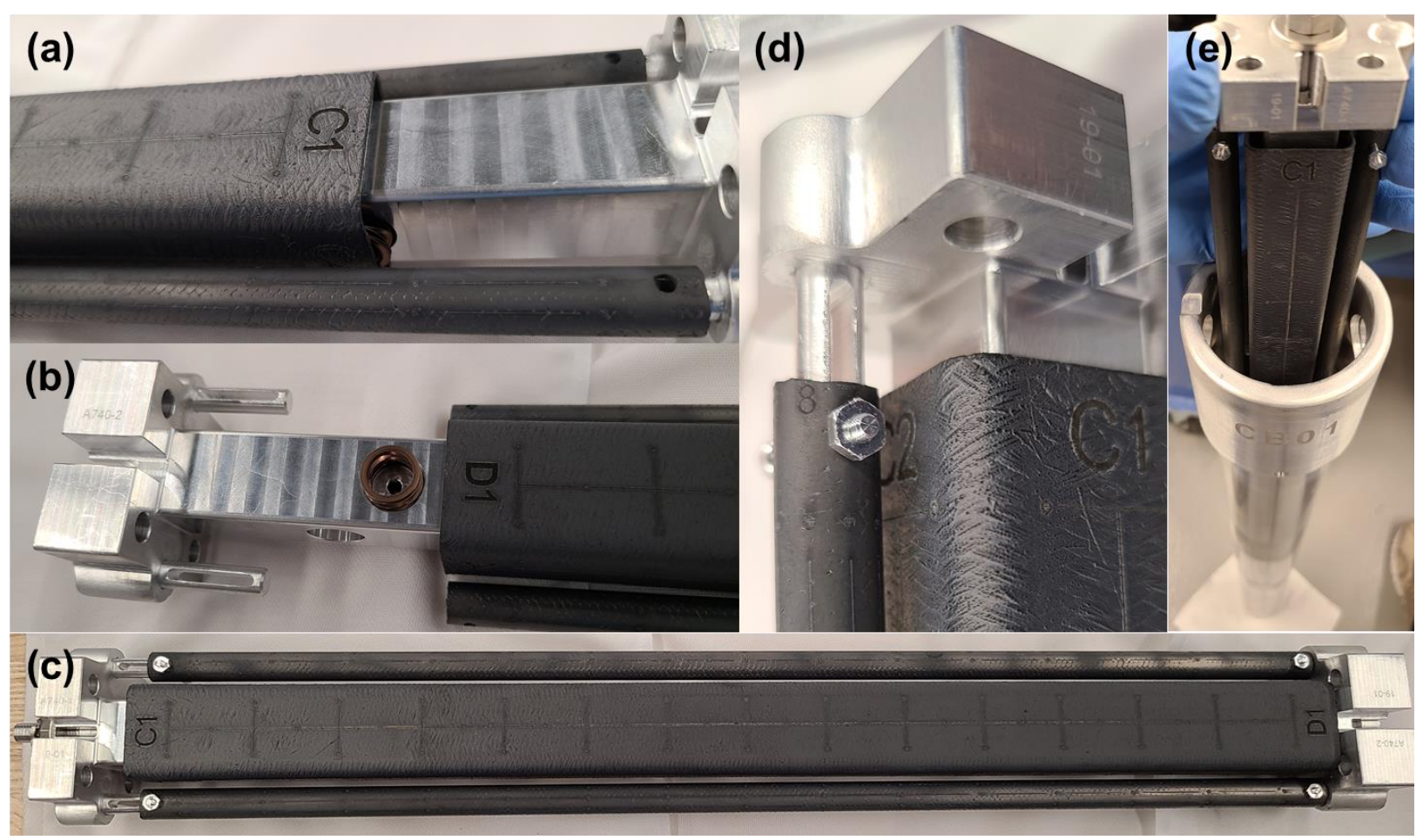

Figure 17. Photographs of the internal assembly. 
The experiment assembly was properly packaged and transported to HFIR along with a fabrication package that includes all material certification, dimensional inspection, weld reports, safety calculations, and signed procedures. The package was reviewed and accepted by all irradiation engineers, quality assurance personnel, and HFIR safety staff. Some of the experiment approval forms are included in the Appendix in this report. The experiment is scheduled for insertion during HFIR cycle 492, which is currently scheduled to run from May 18, 2021 to June 11, 2021.

\section{SUMMARY AND CONCLUSIONS}

This report summarizes the motivation, design, pre-irradiation characterization, and successful assembly of a HFIR irradiation experiment with the goal of validating thermomechanical models for radiation-induced bowing of $\mathrm{SiC} / \mathrm{SiC}$ composite components for LWR applications. Calculations have predicted significant lateral bowing of $\mathrm{SiC} / \mathrm{SiC}$ components during exposure to either a differential radial fast neutron flux gradient or a significant radial temperature gradient during irradiation. This experiment is targeting the former scenario, as the HFIR's reflector positions provide a significant radial fast neutron flux gradient, similar to what might be expected for a BWR channel box positioned at the periphery of the core. The HFIR experiment will irradiate a miniature $\mathrm{SiC} / \mathrm{SiC}$ channel box and two $\mathrm{SiC} / \mathrm{SiC}$ specimens with a prototypic PWR diameter for one to two cycles (each $\sim 25$ days). The specimens will be directly cooled by the reactor coolant, which remains at a temperature of approximately $50-60^{\circ} \mathrm{C}$. Neutronics analyses predict a $\sim 35 \%$ reduction in dose rate from the front face (facing toward the core) to the back face (facing away from the core) of the $30 \mathrm{~mm}$ square channel box specimen. This results in calculated differential radiation-induced swelling of $0.3 \mathrm{vol} \%$ and $0.55 \mathrm{vol} \%$ after one and two irradiation cycles, respectively. The structural analyses predict bowing of $0.60 \mathrm{~mm}$ and $1.02 \mathrm{~mm}$ at the end of one and two cycles of irradiation, respectively. Calculated normal stresses are relatively, on the order of megapascals and less than $13 \mathrm{MPa}$ for all evaluated cases.

In addition to typical dimensional inspections (length, width, depth, and wall thickness), the channel box specimen was engraved with fine markers for mapping local strains and profiled using an optical micrometer to accurately characterize any bowing that may be present before irradiation. Those measurements will be repeated post-irradiation to quantify radiation-induced bowing. The pre-irradiation bowing was measured to be as large as $0.67 \mathrm{~mm}$ on one face and as small as $0.25 \mathrm{~mm}$ on another, indicating that the expected radiation-induced bowing $(0.6 \mathrm{~mm}$ or greater $)$ can be measured. The spacing between engraved markers was measured using a 3D stage and a digital microscope. Additional analysis is being performed to provide a fine adjustment to the marker spacing by determining the distance from the center of each image to the centroid of the engraved markers. It is expected that the spacing can be quantified to within less than $10 \mu \mathrm{m}$, which is equivalent to $\pm 0.01 \%$ linear strain ( $\pm 0.03 \%$ volumetric swelling). The experiment was successfully assembled and is scheduled for insertion during HFIR cycle 492, which is currently scheduled to run from May 25, 2021 to June 18, 2021.

\section{REFERENCES}

1. Katoh, Y., et al., Continuous SiC fiber, CVI SiC matrix composites for nuclear applications: Properties and irradiation effects. Journal of Nuclear Materials, 2014. 448(1-3): p. 448-476.

2. Koyanagi, T., et al., Effects of neutron irradiation on mechanical properties of silicon carbide composites fabricated by nano-infiltration and transient eutectic-phase process. Journal of Nuclear Materials, 2014. 448(1-3): p. 478-486.

3. Ishikawa, T., et al., A Tough, Thermally Conductive Silicon Carbide Composite with High Strength up to $1600^{\circ} \mathrm{C}$ in Air. Science, 1998. 282(5392): p. 1295.

4. Katoh, Y., et al., Dimensional stability and anisotropy of SiC and SiC-based composites in transition swelling regime. Journal of Nuclear Materials, 2018. 499: p. 471-479. 
5. Katoh, Y., et al., Stability of SiC and its composites at high neutron fluence. Journal of Nuclear Materials, 2011. 417(1-3): p. 400-405.

6. George, N.M., et al., Neutronic analysis of candidate accident-tolerant cladding concepts in pressurized water reactors. Annals of Nuclear Energy, 2015. 75: p. 703-712.

7. Terrani, K.A., et al., Silicon Carbide Oxidation in Steam up to $2 \mathrm{MPa}$. Journal of the American Ceramic Society, 2014. 97(8): p. 2331-2352.

8. $\quad$ Pint, B.A., et al., High temperature oxidation of fuel cladding candidate materials in steamhydrogen environments. Journal of Nuclear Materials, 2013. 440(1): p. 420-427.

9. Deck, C.P., et al., Fabrication of SiC-SiC composites for fuel cladding in advanced reactor designs. Progress in Nuclear Energy, 2012. 57: p. 38-45.

10. Deck, C.P., et al., Characterization of SiC-SiC composites for accident tolerant fuel cladding. Journal of Nuclear Materials, 2015. 466: p. 667-681.

11. Zinkle, S.J., et al., Accident tolerant fuels for LWRs: A perspective. Journal of Nuclear Materials, 2014. 448(1-3): p. 374-379.

12. Terrani, K.A., Accident tolerant fuel cladding development: Promise, status, and challenges. Journal of Nuclear Materials, 2018. 501: p. 13-30.

13. Ott, L.J., K.R. Robb, and D. Wang, Preliminary assessment of accident-tolerant fuels on LWR performance during normal operation and under $D B$ and BDB accident conditions. Journal of Nuclear Materials, 2014. 448(1): p. 520-533.

14. Terrani, K.A., et al., Hydrothermal corrosion of SiC in LWR coolant environments in the absence of irradiation. Journal of Nuclear Materials, 2015. 465: p. 488-498.

15. Kondo, S., et al., Effect of irradiation damage on hydrothermal corrosion of SiC. Journal of Nuclear Materials, 2015. 464: p. 36-42.

16. Stempien, J.D., et al., Characteristics of Composite Silicon Carbide Fuel Cladding after Irradiation under Simulated PWR Conditions. Nuclear Technology, 2013. 183(1): p. 13-29.

17. Ben-Belgacem, M., et al., Thermo-mechanical analysis of LWR SiC/SiC composite cladding. Journal of Nuclear Materials, 2014. 447(1-3): p. 125-142.

18. Stone, J.G., et al., Stress analysis and probabilistic assessment of multi-layer SiC-based accident tolerant nuclear fuel cladding. Journal of Nuclear Materials, 2015. 466: p. 682-697.

19. Petrie, C.M., et al., Experimental design and analysis for irradiation of SiC/SiC composite tubes under a prototypic high heat flux. Journal of Nuclear Materials, 2017. 491: p. 94-104.

20. Singh, G., et al., Evaluating the irradiation effects on the elastic properties of miniature monolithic SiC tubular specimens. Journal of Nuclear Materials, 2018. 499: p. 107-110.

21. Singh, G., K. Terrani, and Y. Katoh, Thermo-mechanical assessment of full SiC/SiC composite cladding for LWR applications with sensitivity analysis. Journal of Nuclear Materials, 2018. 499: p. 126-143.

22. Singh, G., et al., Elastic moduli reduction in SiC-SiC tubular specimen after high heat flux neutron irradiation measured by resonant ultrasound spectroscopy. Journal of Nuclear Materials, 2019. 523: p. 391-401.

23. Yueh, K. and K.A. Terrani, Silicon carbide composite for light water reactor fuel assembly applications. Journal of Nuclear Materials, 2014. 448(1-3): p. 380-388.

24. Garzarolli, F., et al., BWR Fuel Channel Distortion. 2011, Advanced Nuclear Technology International: Mölnlycke, Sweden.

25. Snead, L.L., et al., Handbook of SiC properties for fuel performance modeling. Journal of Nuclear Materials, 2007. 371(1-3): p. 329-377.

26. Singh, G., et al., Deformation analysis of SiC-SiC channel box for BWR applications. Journal of Nuclear Materials, 2019. 513: p. 71-85.

27. Singh, G., et al., Parametric Evaluation of SiC/SiC Composite Cladding with UO2 Fuel for LWR Applications: Fuel Rod Interactions and Impact of Nonuniform Power Profile in Fuel Rod. Journal of Nuclear Materials, 2018. 499: p. 155-167. 
28. Cheverton, R.D. and T.M. Sims, HFIR Core Nuclear Design. 1971, Oak Ridge National Laboratory: Oak Ridge, TN.

29. Xoubi, N. and R.T. Primm III, Modeling of the High Flux Isotope Reactor Cycle 400. 2005: Oak Ridge, $\mathrm{TN}$.

30. X-5 Monte Carlo Team, Monte Carlo Team, MCNP-A General Purpose Monte Carlo N-Particle Transport Code, Version 5. 2003, Los Alamos National Laboratory.

31. Norgett, M.J., M.T. Robinson, and I.M. Torrens, A proposed method of calculating displacement dose rates. Nuclear Engineering and Design, 1975. 33(1): p. 50-54.

32. Robinson, M.T. and I.M. Torrens, Computer simulation of atomic-displacement cascades in solids in the binary-collision approximation. Physical Review B, 1974. 9(12): p. 5008-5024.

33. Zinkle, S.J. and C. Kinoshita, Defect production in ceramics. Journal of Nuclear Materials, 1997. 251: p. 200-217.

34. Snead, L.L., et al., Dimensional isotropy of $6 \mathrm{H}$ and $3 \mathrm{C} \mathrm{SiC} \mathrm{under} \mathrm{neutron} \mathrm{irradiation.} \mathrm{Journal} \mathrm{of}$ Nuclear Materials, 2016. 471: p. 92-96. 


Face C1 D1

\begin{tabular}{cccc}
\hline $\begin{array}{c}\text { Marker } \\
\text { ID }\end{array}$ & Z (mm) & X (mm) & $\begin{array}{c}\text { Surface } \\
\text { normal } \\
\text { distance } \\
\text { (mm) }\end{array}$ \\
\hline $\mathbf{1}$ & 577.479 & 70.968 & 93.270 \\
\hline $\mathbf{2}$ & 577.503 & 86.976 & 93.090 \\
\hline $\mathbf{3}$ & 564.797 & 79.064 & 93.220 \\
\hline $\mathbf{4}$ & 552.067 & 71.188 & 93.330 \\
\hline $\mathbf{5}$ & 552.177 & 87.209 & 93.120 \\
\hline $\mathbf{6}$ & 539.398 & 79.225 & 93.210 \\
\hline $\mathbf{7}$ & 526.608 & 71.155 & 93.390 \\
\hline $\mathbf{8}$ & 526.620 & 87.180 & 93.230 \\
\hline $\mathbf{9}$ & 513.905 & 79.266 & 93.370 \\
\hline $\mathbf{1 0}$ & 501.188 & 71.395 & 93.060 \\
\hline $\mathbf{1 1}$ & 501.289 & 87.409 & 93.020 \\
\hline $\mathbf{1 2}$ & 488.515 & 79.433 & 92.970 \\
\hline $\mathbf{1 3}$ & 476.202 & 71.575 & 92.990 \\
\hline $\mathbf{1 4}$ & 476.181 & 87.574 & 93.070 \\
\hline $\mathbf{1 5}$ & 463.499 & 79.638 & 93.040 \\
\hline $\mathbf{1 6}$ & 450.807 & 71.752 & 93.040 \\
\hline $\mathbf{1 7}$ & 450.869 & 87.760 & 93.230 \\
\hline $\mathbf{1 8}$ & 438.120 & 79.754 & 93.120 \\
\hline $\mathbf{1 9}$ & 425.287 & 71.544 & 93.120 \\
\hline $\mathbf{2 0}$ & 425.300 & 87.567 & 93.300 \\
\hline $\mathbf{2 1}$ & 412.580 & 79.634 & 93.290 \\
\hline $\mathbf{2 2}$ & 399.870 & 71.748 & 93.190 \\
\hline $\mathbf{2 3}$ & 399.949 & 87.771 & 93.390 \\
\hline $\mathbf{2 4}$ & 387.171 & 79.765 & 93.200 \\
\hline $\mathbf{2 5}$ & 374.645 & 71.894 & 93.090 \\
\hline $\mathbf{2 6}$ & 374.749 & 87.993 & 93.310 \\
\hline $\mathbf{2 7}$ & 361.958 & 79.965 & 93.170 \\
\hline $\mathbf{2 8}$ & 349.300 & 71.961 & 93.050 \\
\hline $\mathbf{2 9}$ & 349.408 & 88.002 & 93.270 \\
\hline $\mathbf{3 0}$ & 336.841 & 79.997 & 93.170 \\
\hline $\mathbf{3 1}$ & 323.924 & 71.818 & 93.080 \\
\hline $\mathbf{3 2}$ & 324.096 & 87.914 & 93.320 \\
\hline $\mathbf{3 3}$ & 311.377 & 80.001 & 93.220 \\
\hline $\mathbf{3 4}$ & 298.796 & 71.940 & 93.160 \\
\hline $\mathbf{3 5}$ & 298.773 & 88.007 & 93.360 \\
\hline $\mathbf{3 6}$ & 286.168 & 80.059 & 93.220 \\
\hline $\mathbf{3 7}$ & 273.155 & 71.783 & 93.070 \\
\hline $\mathbf{3 8}$ & 273.185 & 87.792 & 93.270 \\
\hline $\mathbf{3 9}$ & 260.515 & 79.874 & 93.100 \\
\hline $\mathbf{4 0}$ & 247.973 & 71.811 & 93.000 \\
\hline $\mathbf{4 1}$ & 247.936 & 87.836 & 93.160 \\
\hline $\mathbf{4 3}$ & 235.377 & 79.894 & 92.990 \\
\hline $\mathbf{4 4}$ & 222.228 & 71.661 & 92.840 \\
\hline & 222.188 & 87.644 & 93.020 \\
\hline
\end{tabular}

Face C2 D2

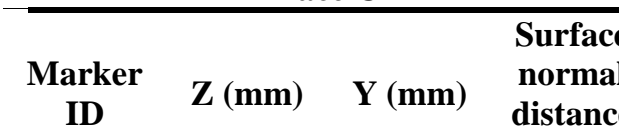

(mm)

\begin{tabular}{|c|c|c|c|}
\hline 1 & 578.454 & 70.810 & 93.980 \\
\hline 2 & 578.583 & 87.042 & 93.505 \\
\hline 3 & 565.708 & 78.889 & 93.819 \\
\hline 4 & 552.930 & 70.794 & 94.078 \\
\hline 5 & 553.141 & 87.021 & 93.656 \\
\hline 6 & 540.415 & 78.991 & 93.918 \\
\hline 7 & 527.492 & 70.901 & 94.108 \\
\hline 8 & 527.667 & 87.071 & 93.696 \\
\hline 9 & 514.893 & 78.945 & 93.898 \\
\hline 10 & 502.125 & 70.953 & 94.137 \\
\hline 11 & 502.340 & 87.197 & 93.676 \\
\hline 12 & 489.607 & 79.092 & 93.858 \\
\hline 13 & 476.890 & 71.072 & 94.117 \\
\hline 14 & 476.898 & 87.320 & 93.756 \\
\hline 15 & 464.297 & 79.047 & 93.985 \\
\hline 16 & 451.380 & 71.023 & 94.177 \\
\hline 17 & 451.583 & 87.277 & 93.826 \\
\hline 18 & 438.917 & 79.162 & 93.945 \\
\hline 19 & 426.214 & 71.029 & 94.107 \\
\hline 20 & 426.336 & 87.308 & 93.706 \\
\hline 21 & 413.108 & 78.693 & 93.885 \\
\hline 22 & 400.932 & 71.329 & 93.967 \\
\hline 23 & 400.822 & 87.245 & 93.696 \\
\hline 24 & 388.127 & 79.286 & 93.665 \\
\hline 25 & 375.466 & 71.299 & 93.767 \\
\hline 26 & 375.258 & 87.177 & 93.536 \\
\hline 27 & 362.496 & 79.212 & 93.595 \\
\hline 28 & 350.121 & 71.129 & 93.607 \\
\hline 29 & 350.041 & 87.222 & 93.666 \\
\hline 30 & 337.377 & 79.182 & 93.585 \\
\hline 31 & 324.698 & 71.121 & 93.507 \\
\hline 32 & 324.632 & 87.276 & 93.686 \\
\hline 33 & 312.281 & 79.255 & 93.645 \\
\hline 34 & 299.499 & 71.217 & 93.517 \\
\hline 35 & 299.615 & 87.303 & 93.706 \\
\hline 36 & 287.037 & 79.340 & 93.715 \\
\hline 37 & 274.240 & 71.286 & 93.557 \\
\hline 38 & 274.324 & 87.400 & 93.725 \\
\hline 39 & 261.695 & 79.320 & 93.675 \\
\hline 40 & 248.939 & 71.279 & 83.547 \\
\hline 41 & 248.944 & 87.355 & 93.845 \\
\hline 42 & 236.329 & 79.247 & 93.655 \\
\hline 43 & 223.524 & 71.273 & 93.407 \\
\hline 44 & 223.617 & 87.440 & 93.755 \\
\hline
\end{tabular}

Marker locations for faces C1 D1 and C2 D2. 
Face C3 D3

\begin{tabular}{|c|c|c|c|}
\hline $\begin{array}{c}\text { Marker } \\
\text { ID }\end{array}$ & $\mathbf{Z}(\mathbf{m m})$ & $\mathbf{X}(\mathbf{m m})$ & $\begin{array}{c}\text { Surface } \\
\text { normal } \\
\text { distance } \\
(\mathrm{mm})\end{array}$ \\
\hline 1 & 577.668 & 71.412 & 93.865 \\
\hline 2 & 577.740 & 87.452 & 93.585 \\
\hline 3 & 565.120 & 79.490 & 93.715 \\
\hline 4 & 552.408 & 71.604 & 93.835 \\
\hline 5 & 552.440 & 87.623 & 93.495 \\
\hline 6 & 539.782 & 79.621 & 93.765 \\
\hline 7 & 526.898 & 71.466 & 93.885 \\
\hline 8 & 526.839 & 87.529 & 93.645 \\
\hline 9 & 514.280 & 79.450 & 93.805 \\
\hline 10 & 501.660 & 71.648 & 93.705 \\
\hline 11 & 501.636 & 87.642 & 93.435 \\
\hline 12 & 489.014 & 79.762 & 93.355 \\
\hline 13 & 476.459 & 71.758 & 93.565 \\
\hline 14 & 476.494 & 87.908 & 93.415 \\
\hline 15 & 463.880 & 79.881 & 93.545 \\
\hline 16 & 450.986 & 71.796 & 93.705 \\
\hline 17 & 451.108 & 87.924 & 93.515 \\
\hline 18 & 438.439 & 79.800 & 93.705 \\
\hline 19 & 425.450 & 71.499 & 93.915 \\
\hline 20 & 425.586 & 87.615 & 93.703 \\
\hline 21 & 412.928 & 79.622 & 93.875 \\
\hline 22 & 400.137 & 71.542 & 94.015 \\
\hline 23 & 400.337 & 87.724 & 93.843 \\
\hline 24 & 387.593 & 79.764 & 93.925 \\
\hline 25 & 375.060 & 72.092 & 93.995 \\
\hline 26 & 374.976 & 88.039 & 93.873 \\
\hline 27 & 362.444 & 79.982 & 93.855 \\
\hline 28 & 349.635 & 72.029 & 93.985 \\
\hline 29 & 349.584 & 88.031 & 93.883 \\
\hline 30 & 336.980 & 79.952 & 93.875 \\
\hline 31 & 324.323 & 72.020 & 93.975 \\
\hline 32 & 324.416 & 87.910 & 93.883 \\
\hline 33 & 311.724 & 79.919 & 93.955 \\
\hline 34 & 299.195 & 72.061 & 94.045 \\
\hline 35 & 299.065 & 88.099 & 93.913 \\
\hline 36 & 286.414 & 80.078 & 93.955 \\
\hline 37 & 273.637 & 71.827 & 93.915 \\
\hline 38 & 273.519 & 87.752 & 93.833 \\
\hline 39 & 260.912 & 79.692 & 93.775 \\
\hline 40 & 248.178 & 71.673 & 93.625 \\
\hline 41 & 248.140 & 87.643 & 93.683 \\
\hline 42 & 235.383 & 79.530 & 93.575 \\
\hline 43 & 222.780 & 71.597 & 93.475 \\
\hline 44 & 222.666 & 87.503 & 93.403 \\
\hline
\end{tabular}

Face C4 D4

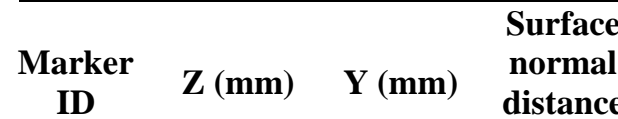

(mm)

\begin{tabular}{|c|c|c|c|}
\hline 1 & 577.245 & 70.091 & 92.560 \\
\hline 2 & 577.068 & 85.885 & 92.250 \\
\hline 3 & 564.368 & 77.957 & 92.477 \\
\hline 4 & 551.823 & 70.123 & 92.630 \\
\hline 5 & 551.664 & 85.978 & 92.330 \\
\hline 6 & 539.161 & 78.165 & 92.547 \\
\hline 7 & 526.589 & 70.362 & 92.620 \\
\hline 8 & 526.424 & 86.209 & 92.270 \\
\hline 9 & 513.559 & 78.208 & 92.430 \\
\hline 10 & 501.035 & 70.304 & 92.570 \\
\hline 11 & 500.785 & 86.169 & 92.250 \\
\hline 12 & 488.296 & 78.275 & 92.400 \\
\hline 13 & 475.764 & 70.408 & 92.670 \\
\hline 14 & 475.514 & 86.248 & 92.210 \\
\hline 15 & 462.993 & 78.247 & 92.470 \\
\hline 16 & 450.418 & 70.412 & 92.720 \\
\hline 17 & 450.246 & 86.279 & 92.330 \\
\hline 18 & 437.720 & 78.456 & 92.480 \\
\hline 19 & 425.117 & 70.363 & 92.690 \\
\hline 20 & 424.985 & 86.373 & 92.310 \\
\hline 21 & 412.419 & 78.501 & 92.440 \\
\hline 22 & 399.613 & 70.421 & 92.600 \\
\hline 23 & 399.653 & 86.423 & 92.250 \\
\hline 24 & 386.968 & 78.448 & 92.400 \\
\hline 25 & 374.272 & 70.394 & 92.500 \\
\hline 26 & 374.239 & 86.442 & 92.140 \\
\hline 27 & 361.467 & 78.244 & 92.270 \\
\hline 28 & 348.755 & 70.142 & 92.570 \\
\hline 29 & 348.753 & 86.213 & 92.180 \\
\hline 30 & 336.149 & 78.239 & 92.340 \\
\hline 31 & 323.489 & 70.300 & 92.670 \\
\hline 32 & 323.549 & 86.234 & 92.270 \\
\hline 33 & 310.991 & 78.285 & 92.590 \\
\hline 34 & 298.317 & 70.355 & 92.850 \\
\hline 35 & 298.262 & 86.349 & 92.460 \\
\hline 36 & 285.739 & 78.339 & 92.770 \\
\hline 37 & 273.079 & 70.449 & 93.090 \\
\hline 38 & 273.066 & 86.331 & 92.670 \\
\hline 39 & 260.324 & 78.196 & 93.020 \\
\hline 40 & 247.556 & 70.166 & 93.300 \\
\hline 41 & 247.534 & 86.257 & 92.930 \\
\hline 42 & 234.899 & 78.209 & 93.100 \\
\hline 43 & 222.063 & 70.080 & 93.320 \\
\hline 44 & 222.122 & 86.192 & 92.980 \\
\hline
\end{tabular}

Marker locations for faces C3 D3 and C4 D4. 
Target ID:

Irradiation Conditions

Number cycles

First Cycle Goal

Capsule Fabrication

\begin{tabular}{|l|c|c|c|c|c|c|}
\hline \multicolumn{1}{|c|}{ Component } & Drawing & Rev. & Part & Material & Count & Comment \\
\hline Holder Weldment & X3E020977A738 & 1 & 1 & Al 6061 & 1 & \\
\hline Channel Box Internal Subassembly & X3E020977A765 & 1 & 1 & N/A & 1 & \\
\hline
\end{tabular}

X3E020977A741 Rev.1

\begin{tabular}{|c|c|c|c|}
\hline \multirow{2}{*}{ Approvals } & \multirow{2}{*}{\multicolumn{3}{|c|}{ Build }} \\
\hline & & & \\
\hline Performed by: & 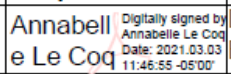 & $\begin{array}{l}\text { David } \\
\text { Bryant }\end{array}$ & 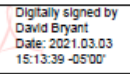 \\
\hline be & 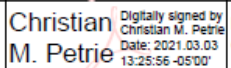 & $\begin{array}{l}\text { Nicholas } \\
\text { George R }\end{array}$ & 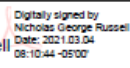 \\
\hline
\end{tabular}

N/A

$\mathrm{N} / \mathrm{A}$

\begin{tabular}{|c|c|c|}
\hline FAB IR & ID & Mass $(\mathbf{g})$ \\
\hline 21194 & CBH & 4173.0500 \\
\hline N/A & CBOXInt & 718.3411 \\
\hline
\end{tabular}

\section{Experiment assembly fabrication request sheet.}

\section{Capsule Fabrication Request Sheet}

\section{Target ID:}

Irradiation Conditions

Number cycles

First Cycle Goal

Assembly drawing

Capsule Fabrication

\begin{tabular}{|l|c|}
\hline \multicolumn{1}{|c|}{ Component } & \\
\hline Pin & $\times 3$ \\
\hline Bottom cap & $\times 3$ \\
\hline EPRI Specimen Holder Upper Ring & $\times 3 E$ \\
\hline Holder Half, A & $\times 3 E$ \\
\hline Holder Half, B & $\times 3 E$ \\
\hline
\end{tabular}

СB01

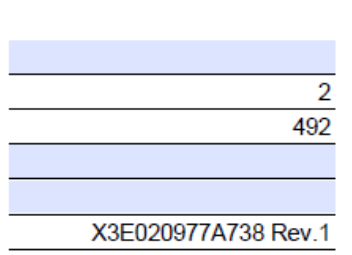

\begin{tabular}{|c|c|c|c|}
\hline \multirow{2}{*}{ Approvals } & \multirow{2}{*}{\multicolumn{3}{|c|}{ Reruest }} \\
\hline & Request & & \\
\hline Performed by: & 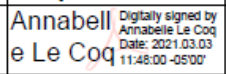 & $\begin{array}{l}\text { David } \\
\text { Bryant }\end{array}$ & 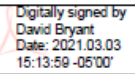 \\
\hline Che & 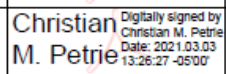 & $\begin{array}{l}\text { Nicholas } \\
\text { George Rus }\end{array}$ & 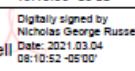 \\
\hline
\end{tabular}

\begin{tabular}{|c|c|c|c|c|c|c|c|c|c|}
\hline Drawing & Rev. & Part & Material & Count & Comment & MAT IR & FAB IR & ID & Mass $(\mathbf{g})$ \\
\hline X3E020977A738 & 1 & 2 & Al 6061 & 1 & & 20962 & 20964 & N/A & \\
X3E020977A605 & A & 1 & Al 6061 & 1 & & 20957 & 20957 & $19-01$ & \\
X3E020977A605 & A & 3 & Al 6061 & 1 & & 20958 & 20958 & $19-01$ & \multirow{2}{*}{4173.0500} \\
X3E020977A739 & 1 & 1 & Al 6061 & 1 & & 20961 & 20961 & N/A & \\
\cline { 1 - 8 } X3E020977A739 & 1 & 2 & Al 6061 & 1 & & 20961 & 20961 & N/A & \\
\hline
\end{tabular}

Experiment holder fabrication request sheet. 
Target ID:

Irradiation Conditions

Number cycles

First Cycle Goal

Assembly drawing

Capsule Fabrication

\begin{tabular}{|c|c|c|c|c|c|c|c|c|c|c|}
\hline Component & Drawing & Rev. & Part & Material & Count & Comment & MAT IR & FAB IR & ID & Mass $(g)$ \\
\hline Tie Rod & X3E020977A740 & 2 & 3 & Al 6061 & 1 & & 20960 & 20960 & N/A & 39.6009 \\
\hline Channel Box Specimen & X3E020977A740 & 2 & 4 & $\mathrm{SiC}$ & 1 & & 21188 & 21188 & $C D$ & 100.2936 \\
\hline Upper Box Support Weldment & X3E020977A764 & 1 & 1 & Al 6061 & 1 & & $\mathrm{~N} / \mathrm{A}$ & $\mathrm{N} / \mathrm{A}$ & UpBSW & 239.7018 \\
\hline Lower Box Support Weldment & X3E020977A764 & 1 & 2 & Al 6061 & 1 & & $\mathrm{~N} / \mathrm{A}$ & N/A & LowBSW & 265.9176 \\
\hline \multirow[t]{2}{*}{ Cladding Specimen } & \multirow[t]{2}{*}{ X3E020977A764 } & \multirow[t]{2}{*}{1} & \multirow[t]{2}{*}{5} & \multirow[t]{2}{*}{$\mathrm{SiC}$} & \multirow[t]{2}{*}{2} & & \multirow[t]{2}{*}{21195} & \multirow[t]{2}{*}{21195} & 01 & 29.7997 \\
\hline & & & & & & & & & 22 & 29.4967 \\
\hline Pin & X3E020977A764 & 1 & 4 & Al 6061 & 4 & & 20962 & 20963 & N/A & 1.3391 \\
\hline Hex nut, 2-56 & 90670A150 & \multicolumn{2}{|c|}{$\frac{1}{N / A}$} & Al 6061 & 4 & cage code: 39428 & 21190 & 21190 & $\mathrm{~N} / \mathrm{A}$ & 0.2649 \\
\hline Wave spring & CS050-L4-S17 & \multicolumn{2}{|c|}{$\mathrm{N} / \mathrm{A}$} & $17-7 \mathrm{SS}$ & 8 & cage code: 51814 & 21189 & 21189 & N/A & 4.7731 \\
\hline Washer, 1/4" & 91525A416 & \multicolumn{2}{|c|}{ N/A } & $316 \mathrm{SS}$ & 1 & cage code: 39428 & 21191 & 21191 & N/A & 3.6427 \\
\hline \begin{tabular}{|l|} 
Locknut, $1 / 4 "-28$ \\
\end{tabular} & 91853A515 & \multicolumn{2}{|c|}{ N/A } & $18-8 \mathrm{SS}$ & 1 & cage code: 39428 & 21192 & 21192 & N/A & 3.2689 \\
\hline Cotter pin, $1 / 16^{\prime \prime}$ x 1/2" LG & $98355 \mathrm{~A} 010$ & \multicolumn{2}{|c|}{ N/A } & $316 \mathrm{SS}$ & 1 & cage code:39428 & 21193 & 21193 & N/A & 0.2421 \\
\hline & & & & & & & & & Total Mass & 718.3411 \\
\hline
\end{tabular}

Experiment internal fabrication request sheet.

\section{Capsule Fabrication Request Sheet}

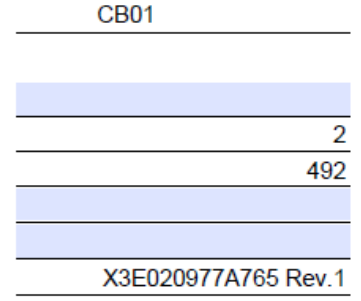

\begin{tabular}{|c|c|c|c|}
\hline & Request & Build & \\
\hline Performed by: & 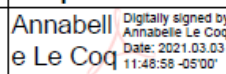 & $\begin{array}{l}\text { David } \\
\text { Bryant }\end{array}$ & 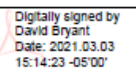 \\
\hline Checked by: & 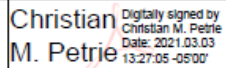 & $\begin{array}{l}\text { Nicholas } \\
\text { Seorge Russell }\end{array}$ & 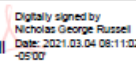 \\
\hline
\end{tabular}

Page 1 of 1 Date $3 / 3 / 2021$
Target ID:

Irradiation Conditions

Number cycles

First Cycle Goal

Assembly drawing

Capsule Fabrication

\begin{tabular}{|c|c|c|c|c|c|c|c|c|c|c|}
\hline Component & Drawing & Rev. & Part & Material & Count & Comment & MAT IR & FAB IR & ID & Mass $(\mathrm{g})$ \\
\hline Box support, Lower & X3E020977A7440 & 2 & 2 & Al 6061 & 1 & & 20959 & 20959 & $19-01$ & \multirow{2}{*}{265.9176} \\
\hline Slotted pin & X3E020977A764 & 1 & 3 & Al 6061 & 2 & & 19728 & 19728 & $\mathrm{~N} / \mathrm{A}$ & \\
\hline
\end{tabular}

\section{Approvals}

\begin{tabular}{|c|c|c|c|}
\hline & Request & Build & \\
\hline Performed by: & 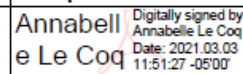 & \begin{tabular}{|l} 
David \\
Bryant
\end{tabular} & 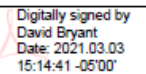 \\
\hline Checked by: & 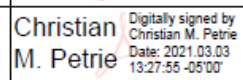 & \begin{tabular}{|l} 
Nicholas \\
George Russel
\end{tabular} & 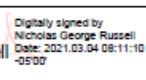 \\
\hline
\end{tabular}

\section{Lower internal support fabrication request sheet.}




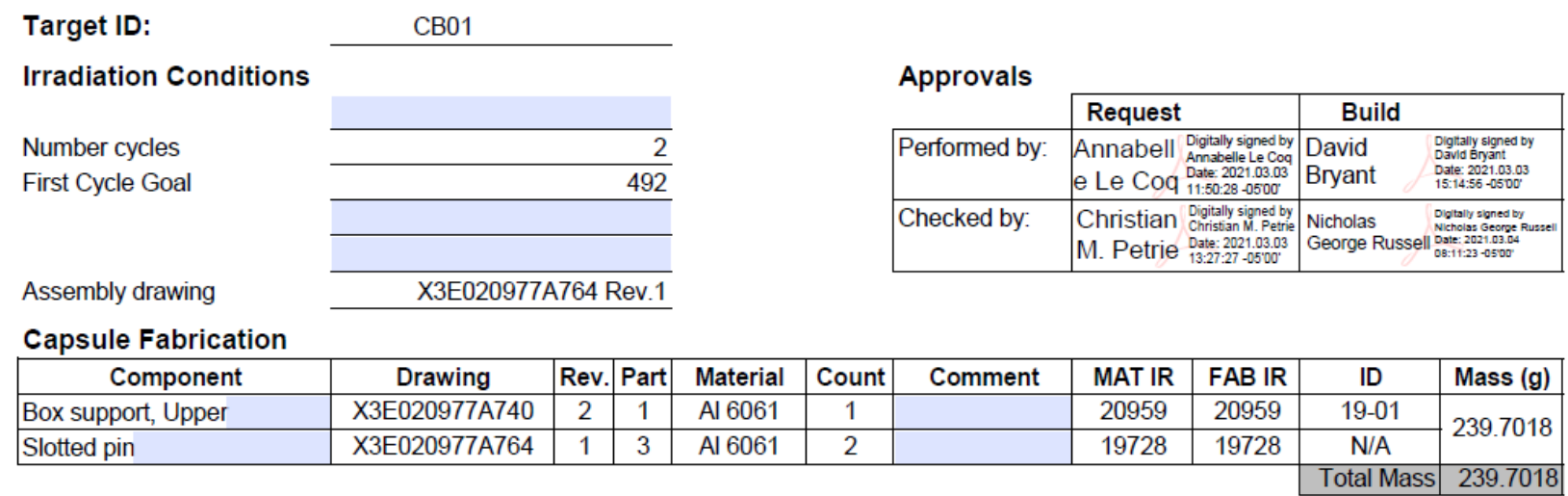

\section{Upper internal support fabrication request sheet.}

